Review

\title{
Polyester Dendrimers: Smart Carriers for Drug Delivery
}

\section{Jean-d'Amour K. Twibanire ${ }^{1,2, *}$ and T. Bruce Grindley ${ }^{1, *}$}

1 Department of Chemistry, Dalhousie University, 6274 Coburg Road, P.O. Box 15000, Halifax, NS B3H 4R2, Canada

2 CanAm Bioresearch Inc., Winnipeg, MB R3T 0P4, Canada

* Authors to whom correspondence should be addressed; E-Mails: twibanire@ dal.ca (J.K.T.); bruce.grindley@dal.ca (T.B.G.); Tel.: +1-902-494-2041 (T.B.G.); Fax: +1-902-494-1310 (T.B.G).

Received: 29 November 2013; in revised form: 3 January 2014 / Accepted: 8 January 2014 /

Published: 15 January 2014

Abstract: Polyester dendrimers have been shown to be outstanding candidates for biomedical applications. Compared to traditional polymeric drug vehicles, these biodegradable dendrimers show excellent advantages especially as drug delivery systems because they are non-toxic. Here, advances on polyester dendrimers as smart carriers for drug delivery applications have been surveyed. Both covalent and non-covalent incorporation of drugs are discussed.

Keywords: polyester dendrimers; biocompatibility; drug delivery; smart carriers; drug delivery pathways; polymersomes

\section{Abbreviations:}

BACPT 7-butyl-10-aminocamptothecin

bis-HMPA 2,2-bis(hydroxymethyl)propanoic acid

BNCT boron neutron capture therapy

COMU 1-[(1-(cyano-2-ethoxy-2-oxoethylideneaminooxy)dimethylaminomorpho-

CPEGC citric acid-polyethylene glycol-citric acid

DBU 1,8-diazabicyclo[5.4.0]undec-7-ene

DIC $\quad N, N^{\prime}$-diisopropylcarbodiimide

DIEA diisopropylethylamine

DLSP drug-loaded degradable dendrimer-like star polymer

DMAP 4-dimethylaminopyridine

DOX doxorubicin 
EPR enhanced permeability and retention

FA-DLSP folate-functionalized degradable amphiphilic dendrimer-like star polymer

FDA United States food and drug administration

10HCPT 10-hydroxycamptothecin

MTX methotrexate

ROP ring-opening polymerization

PAMAM polyamidoamine

PEG poly(ethylene oxide)

PEO poly(ethylene oxide)

PEPE polyester-co-polyether

PLLA poly(L-lactide)

TATU 2-(1H-7-azabenzotriazole-1-yl)-1,1,3,3-tetramethyluronium tetrafluoroborate

TBTU 2-(1H-benzotriazole-1-yl)-1,1,3,3-tetramethyluronium tetrafluoroborate

TFA trifluoroacetic acid

\section{Introduction}

The concept of using high molecular weight polymeric systems as potential drug delivery systems was initially introduced by Ringsdorf [1,2] and Kopeček [3,4]. In chemotherapy, the use of high molecular weight systems results in enhanced targeting of tumor tissue and improved efficiency of the treatment [5-7], an effect explained in part by the enhanced permeability and retention (EPR) phenomenon observed in tumor tissues [8-10]. The EPR effect is the property by which certain sizes of molecules such as liposomes and macromolecular drugs tend to accumulate in tumor tissues much more than they do in normal tissues [8-11]. A good drug molecule must selectively target and bind the receptor microenvironment to ultimately elicit an appropriate biological response. A large number of newly developed drug molecules however, are rejected by the pharmaceutical industry and will never benefit a patient because of poor bioavailability caused by low water solubility and/or poor cell membrane permeability. In addition, a good number of launched drugs exhibit suboptimal performance for the same reasons. Consequently, efficient ways of enhancing bioavailability and biocompatibility of new drugs are of particular interest. Dendrimers offer a particularly attractive alternative as drug delivery systems as they offer a high drug-loading capacity either by encapsulation or conjugation [12-15]. Encapsulation and conjugation of drugs with dendrimers have shown immense utility for delivery of hydrophobic drugs (enhancing solubility) [16,17], labile drugs (sheltering from harsh surroundings), and small molecule drugs (avoiding fast elimination and exposure to healthy tissues). Interest in the use of dendrimers for drug delivery and medicinal applications has mushroomed in the last few years [18-49] and numerous reviews have appeared on dendrimers in drug delivery and biomedical applications [50-55].

Certain unique dendritic features clearly set these compounds apart as special and optimum nanoscale carriers in medical applications. These unique features include polyvalency, high degree of branching, high solubility, globular architecture and most importantly, their well-defined architectures 
(monodispersity) which translate into a more consistent well-defined polymer that brings better reproducibility of results. The success of dendritic nanoparticles for drug delivery applications largely depends on the ability of scientists to design smart carriers with the ability to overcome drug leakage, immunogenicity, cytotoxicity, reticuloendothelial system uptake, and hemolytic toxicity among other shortcomings. One strategy to overcome these shortcomings is to use polyester dendrimers which have been shown to be non-toxic and biocompatible [19,56-60]. By attaching a drug to a suitable carrier, it is possible to enhance its aqueous solubility, increase its circulation half-life, target certain tissues, improve drug transit across biological barriers, and slow drug metabolism [61-66]. Optimization of these features to maximize drug bioavailability to diseased tissues while minimizing drug exposure to healthy tissues, results in improved therapeutic efficacy.

Polyester dendrimers have been shown to be associated with various novel applications and are particularly promising as drug carriers. The use of biodegradable dendrimers emerged as a strategy to produce desirable large molecular weight carriers that achieve high accumulation and retention in diseased tissues, but allow rapid and safe elimination of non-toxic dendrimer fragments into the urine.

\section{Dendrimers and Common Drug Delivery Pathways}

\subsection{Oral Drug Delivery}

Amongst the many routes for drug delivery, the oral route is preferred [18,67-70], probably because of patience preference. For many existing and new drugs such as therapeutic peptides, peptidomimetics, oligonucleotides and others, oral bioavailability is in many cases below acceptable levels. To overcome this problem and to guarantee a sufficient high oral uptake, the use of efficient oral drug delivery systems is important. Transport of a dendrimer through the epithelial layer of the gastrointestinal tract depends upon the dendrimer's characteristics. Housing a drug inside a soluble dendrimer host not only solubilizes it but also allows it to bypass using a transporter protein for movement from the intestinal tract into the blood. Often drugs are not compatible with use of the protein transporter system that is designed to pass nutrients. The oral route using dendrimers looks very promising especially with anticancer and antihypertensive drugs [23,71-75].

\subsection{Transdermal Drug Delivery}

The human skin is a readily accessible surface for drug delivery. Transdermal drug delivery can be used as an alternative route of administration to accommodate patients who cannot tolerate oral dosage forms. It is also of great advantage in patients who are nauseated or unconscious. Drugs that cause gastrointestinal upset can be good candidates for transdermal delivery because this method avoids direct effects on internal organs such as the stomach and intestine. In addition, drugs that are degraded by the enzymes and acids in the gastrointestinal system may also be good targets. However, many new drugs are hydrophobic causing low water-solubility that results in insufficient levels of drug delivered into cells. Water soluble and biocompatible dendritic species are known to improve drug solubility and plasma circulation time via transdermal formulations and to deliver drugs quickly and effectively [72,76-81]. In this regard, dendrimers have been shown to be useful as transdermal drug 
delivery systems for various types of medications [77,80,81], including anticancer, antiviral, nonsteroidal anti-inflammatory and antihypertensive drugs.

\subsection{Ocular Drug Delivery}

Ocular drug delivery has been a major challenge to pharmacologists and drug delivery researchers due to the eye's unique anatomy and physiology [82]. The most common route of administration for the treatment of various ocular diseases is the topical application of drugs to the eye. Because of drainage of the excess fluid via the nasolacrimal duct and elimination by tear turnover, the intraocular bioavailability of topically administered drugs is poor. Research advances have shown that the use of drug delivery systems such dendrimers can help to overcome the many disadvantages and complications associated with ocular drug delivery [83,84].

\subsection{Drug Delivery by Injection}

Drug administration by injection encompasses intramuscular (IM), intravenous (IV), and subcutaneous (SC) drug administrations. Medication delivered via injection often acts rapidly and has essentially high bioavailability. Injections are useful for drugs that are poorly absorbed or ineffective when given orally. Injection is also an excellent way to administer drugs to patients who are nauseated or unconscious. However, because the drug is delivered to the site of action extremely rapidly with IV injection, there is a risk of overdose if the dose has been calculated incorrectly, and there is an increased risk of side effects if the drug is administered too rapidly. Numerous reports of IV administered dendrimer-drug complexes have appeared [85-89]. For example, 2'-(benzo[1,2-c] 1,2,5oxadiazol-5(6)-yl( $\mathrm{N}_{1}$-oxide) methylidene)-1-methoxy methane hydrazide presents antichagasic activity but has low water solubility. Guest-host interactions with a dendrimer result in good drug solubilization. These interactions can be controlled by varying the solution $\mathrm{pH}$, allowing drug deliverance [85].

\section{Covalent and Non-Covalent Dendrimer-Drug Systems}

Polymer therapeutics includes polymeric drugs, polymer-drug conjugates, polymer-protein conjugates, polymer-DNA complexes, and polymeric micelles to which drugs are covalently linked and/or physically entrapped [90-95]. Conventionally, nanoscale therapeutics is derived from polymer-drug conjugates, in which a drug is covalently bound through cleavable linkages such as the pH sensitive cis-aconityl, hydrazine, and acetal linkages [56,90-98]. On the other hand, supramolecular drug delivery systems based on block copolymer micelles or dendritic systems have shown great promise and utility for tumor targeting and drug delivery [8,19,99-103]. Both covalent and non-covalent systems can utilize the enhanced permeability and retention (EPR) phenomenon [9-11]. Major disadvantages of drug delivery systems based on non-covalent entrapment of drugs into core-shell architectures are the lack of kinetic stability of polymer micelles that are susceptible to infinite dilution arising from their administration and poor drug loading capacity. Nevertheless, reports of simple yet effective and versatile approaches that employ non-covalent interactions for mediating 
the formation of macromolecular assemblies to encapsulate, transport, and release therapeutic agents have appeared [104-108].

To achieve positive results in the encapsulation and release of a guest drug, suitable dendrimer-guest partners must be carefully selected. For example, the complexation of opposite charged PEG block copolymers with cationic amino methacrylates or anionic styrene sulfonates has been explored [109]. Polymer-drug partners with specific acid-base interactions between hydrophobic drug molecules $\left(\mathrm{R}_{1}-\mathrm{COOH}\right)$ and polymer segments $\left(\mathrm{NH}_{2}-\mathrm{R}_{2}\right)$ improved the drug loading capacity [110]. Hydrogen bonding formation between the guest drug and the host polymer has also been explored [111-116].

Another innovative way to deliver a drug conjugated to or adhering to a dendrimer is to further conjugate the dendrimer to aptamers [117-120]. The aptamers can be selected to bind to specific cell types, such as cancer or other disease cells with different cell-surface biomarkers. For example, carboxy-coated PAMAM dendrimers were conjugated to amino groups of the aptamers by forming activated esters from the carboxy groups $[117,118,121]$. Such an approach could easily be adapted to carboxy-coated polyester dendrimers that would have the advantage of having low toxicity and biocompatibility associated with polyester dendrimers.

\section{Polyester Dendrimers}

\subsection{Attractive Features of Polyester Dendrimers for Drug Delivery Applications}

Improving the therapeutic index of drugs is a major incentive for innovation in many therapeutic areas such as cancer, inflammatory and other infectious diseases like HIV. Polyester dendrimers constitute an attractive class of compounds because they are biodegradable and biocompatible [61]. In addition, whenever they have been tested, they have been found to have low toxicity $[56,122,123]$, unlike other dendrimers [124]; this is extremely important if these molecules are to be used as frameworks for drug delivery and other biological applications in biological systems. Like other dendrimers in general, polyester dendrimers have interior void spaces which may be used to encapsulate small molecule drugs, metals, or imaging moieties. Not only does encapsulation increase the half-life of the drug due to controlled release, it also reduces the drug toxicity due to lessened drug exposure to healthy tissues en route to the receptor microenvironment or diseased tissues. Because a prolonged therapeutic level can be achieved due to a sustained drug release [125], the frequency of dosing can be reduced which would in turn contribute to improved compliance by the patient. The surface hydroxyl groups of polyester dendrimers are responsible for their high solubility and miscibility and for their high reactivity. These highly reactive surfaces can be modified to optimize bio-distribution, receptor mediated targeting, and/ or controlled release of encapsulated active moieties or attached drugs [57]. In addition, polyester dendrimers have labile ester functionalities which are steadily hydrolyzed in vivo to release entrapped or covalently attached drugs. Higher generation polyester dendrimers can easily be prepared with facile synthesis of other dendrimers and a variety of methods have been reported for ester bond formation [126-135]. The synthesis of polyester dendrimers in general [135] and those derived from bis-2,2-hydroxymethylpropanoic acid (bis-HMPA) in particular [58] have been reviewed. A recent attractive strategy is the use of uronium-based coupling agents, TBTU [136], TATU [137], and COMU [138] to promote ester bond formation between 
carboxylic acid dendrons and polyalcoholic cores [139]. This regioselective esterification of primary hydroxyls in the presence of non-protected secondary or tertiary hydroxyls (Grindley-Twibanire esterification) is efficient for the $O-6$ acylation on carbohydrates and it has recently been applied in the divergent construction of a second-generation mixed polyester dendrimer [139], the preparation of Lyme disease glycolipid antigens [140], and the direct synthesis of maradolipids and other trehalose 6-monoesters and 6,6'-diesters [141]. The reduction in synthetic steps means less cost for the final product and in addition, the elimination of protection/deprotection steps leads to minimized chemical wastes, which is important as we move towards a greener chemistry and a greener world.

\subsection{Advances in Polyester Dendrimers for Drug Delivery Applications}

Fréchet and coworkers have contributed tremendously to the area of polyester dendrimers [56,57,96,97,126,142-147]. In early 2000, this group prepared and evaluated various dendritic architectures composed of a polyester dendritic scaffold based on the monomer unit bis-HMPA for their suitability as drug carriers both in vitro and in vivo [63]. The systems were found to be water soluble and nontoxic. In addition, the potent anticancer drug, doxorubicin (DOX), was covalently bound via a hydrazine linkage to a high molecular weight 3-arm poly(ethylene oxide)-dendrimer hybrid as shown in Figure 1. The highly potent anticancer agent doxorubicin is a fluorescent compound, and this provides a convenient analytical tool for monitoring the biodistribution of the polymer-DOX conjugate. The polymer-DOX conjugate showed no significant accumulation in any vital organ including the liver, heart, and lungs. This is a significantly different distribution pattern than is observed for the free drug, which partitions into a variety of organs such as the liver and heart [148].

Figure 1. Doxorubicin-functionalized model polyester dendrimer for therapeutic studies.

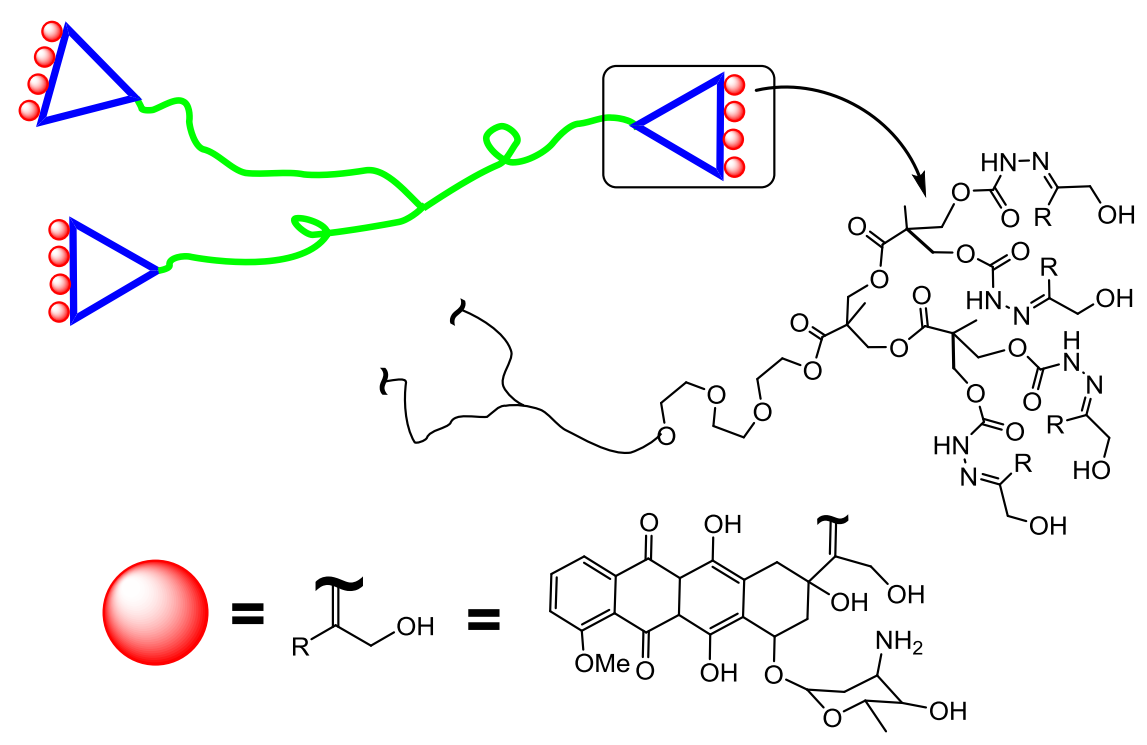

The polymer-DOX conjugate had a circulation half-life of $72 \mathrm{~min}$, which is significantly longer than the half-life of the free doxorubicin $(\sim 8 \mathrm{~min})$. This is an indication that the dendritic form of the carrier favourably enhanced the pharmacokinetics and the biodistribution of the drug. The results of the cytotoxicity of drug-polymer conjugate in vitro suggested that polyester dendrimer-based systems do not exhibit a significant toxic effect and the drug release rates from the hydrazine linker encouraged 
further evaluation of the model compound as a polymeric drug carrier. In vitro evaluation of the conjugate was performed in various cancer cell lines to compare the cytotoxic activity of the bound drug in relation to the free drug. The three cell lines examined exhibited a range of sensitivity to the free doxorubicin, from $0.025 \mu \mathrm{g} / \mathrm{mL}$ for B16F10 to $0.62 \mu \mathrm{g} / \mathrm{mL}$ for the MDA-MB-435 cell lines. In all three cell lines examined, the free drug was considerably more potent than the drug-polymer conjugate; 6-fold in the B16F10 cells, 50-fold in the MDA-MB-231, and 9-fold in the MDA-MB-435 cells. In summary, the dendrimer-DOX system shows no accumulation in any vital organ examined, including the liver, heart, and lungs. The results suggest that this polyester dendritic backbone is a highly water soluble, nontoxic, and biocompatible polymer [63].

After contradictory reports [63,149], the hydrolysis kinetics of low molecular weight and polymeric doxorubicin hydrazone carboxylates were reinvestigated [150]. It is now believed that DOX toxicity was likely not observed due to the specific linkage to DOX, which allowed intramolecular cyclization to produce an inactive version of DOX [150].

The system evaluated here had a molecular weight of $22,550 \mathrm{~g} / \mathrm{mol}$ prior to functionalization. To further increase the circulation half-life to effectively exploit the EPR phenomenon [8-10], higher molecular weight systems were prepared and evaluated $[13,56]$. The biological evaluation of a library of eight polyester dendrimer-poly(ethylene oxide) (PEO) bow-tie hybrids of the form shown in Figure 2 was described [56]. Evaluated polymers were designed to include a range of MWs (from 20,000 to $160,000)$ and architectures with the number of PEO arms ranging from two to eight. For these bow-tie dendrimers, the number of PEO arms can be adjusted to provide polymers of different architectures by using dendrons of different generations. By tuning the combination of the number of PEO arms and their length, a variety of MWs can be prepared. Accordingly, a small library of eight polymers was prepared where the PEO functionalized dendron was varied from the first to the third generation (two to eight arms). PEO arms with MWs of 5000-20,000 were used to prepare polymers with MWs ranging from 20,000 to 160,000 since one goal here was to prepare long-circulating drug carriers.

Figure 2. Fréchet's polyester dendrimer-[poly(ethylene oxide)]. A "Bow-tie" type dendrimer.

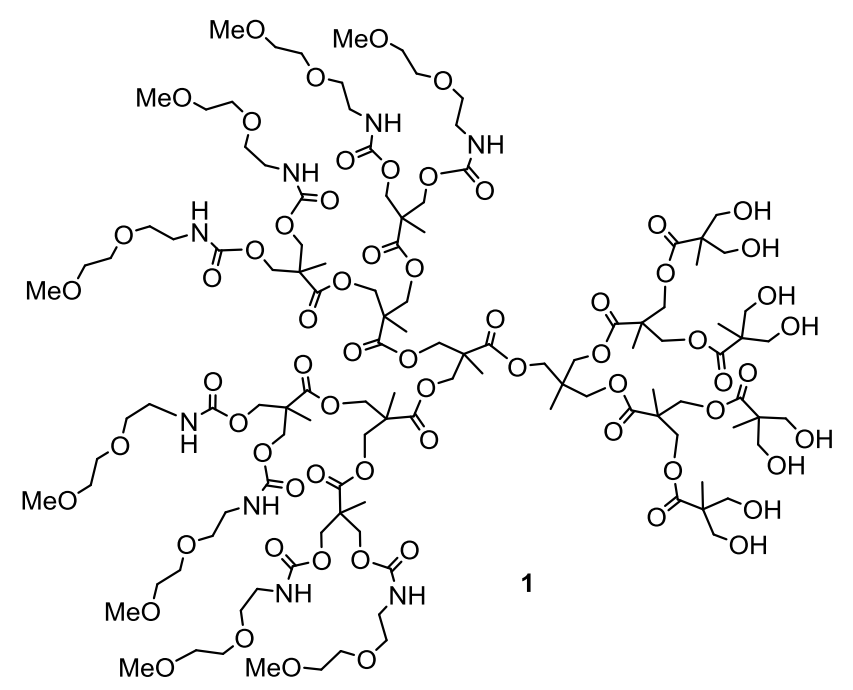

In order to track the polymers in vivo, some dendrimer hydroxyl groups of each bow-tie polymer were statistically converted to tyramine carbamates as shown in Scheme 1, by activation of the 
polymers with a limited amount of 4-nitrophenyl chloroformate, followed by excess tyramine [56]. After investigating the in vitro cytotoxicity of the polymers, the in vitro biodegradability, the biodistribution, and the biodistribution in tumored mice, the following observations and conclusions were made. In vitro experiments revealed that the polymers were nontoxic to cells and were degraded to lower MW species at $\mathrm{pH} 7.4$ and $\mathrm{pH}$ 5.0. Biodistribution studies with ${ }^{125}$ I-radiolabeled polymers showed that all carriers with MWs of 40,000 and greater had plasma circulation times in excess of $24 \mathrm{~h}$, while those with lower MWs were cleared more rapidly with significant quantities excreted in the urine. Comparison of the renal clearances for the four-arm versus eight-arm polymers indicated that the more branched polymers were excreted more slowly into the urine, a result attributed to their decreased flexibility. Polymers with "two arms" which have essentially linear architectures were rapidly taken up by the liver. The biodistribution results of two long-circulating high MW polymers in mice bearing subcutaneous B16F10 tumors indicated high levels of tumor accumulation.

Scheme 1. Functionalzation of bow-tie dendrimers for biodistribution studies.

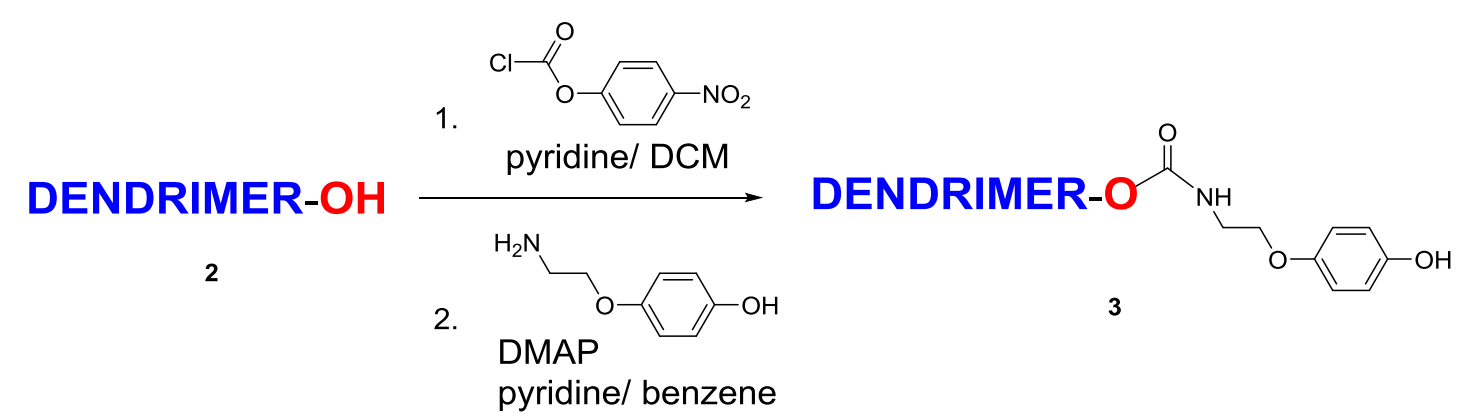

Overall, the attractive features of this type of branched carriers including degradability, lack of toxicity, long circulation half-lives, and high levels of tumor accumulation make them very promising for therapeutic applications [56]. In addition, because a long blood circulation time is a prerequisite for tumor targeting using the EPR effect [9,151], it is evident that bow ties with molecular masses $>40 \mathrm{kDa}$ are acceptable candidates for passive tumor targeting. Accordingly, this type of systems was further evaluated (in mice with cancerous tumors) as drug delivery systems with the highly potent doxorubicin as the attached drug [57].

For this therapeutic study in mice with cancerous tumors, a [G-3]-( $\left(\mathrm{PEO}_{5 \mathrm{k}}\right)_{8}$-[G-4]- $(\mathrm{OH})_{16}$ bow tie with a molecular mass of $45 \mathrm{kDa}$ was used because it is more branched and contains less PEO per dendron than the other prepared bow ties [57]. Highly branched bow ties exhibit good steric protection of their payloads, whereas bow ties containing just enough PEO to prevent renal clearance have higher theoretical drug-loading capacities [56,57]. In order to achieve a drug loading comparable to polymers or liposomes that have been previously used to deliver DOX $(\approx 10 \mathrm{wt} \%)[152,153]$, the bow tie with 16 hydroxyl groups provided a sufficient drug payload given that the yield of the hydrazone formation with polyester dendrimers is roughly 50\% [13,63]. The attachment of doxorubicin via $\mathrm{pH}$-sensitive hydrazone linkages is shown in Scheme $2[57,63]$.

Several detailed experiments were conducted on the dendrimer-DOX conjugate including cytotoxicity in cell culture, biodistribution in tumor-implanted mice, and chemotherapy experiments on C-26 colon carcinoma [57]. This tumor model was chosen because it represents a challenging cancer cell line that is relatively sensitive to free DOX in cell culture but not in vivo, a finding that has been 
attributed to the inability of the drug to attain sufficient intra-tumor concentrations [154]. Additionally, a positive control experiment (using Doxil) was also conducted in order to evaluate the effectiveness of dendrimer-DOX in comparison to the FDA-approved doxorubicin carrier Doxil.

Scheme 2. Functionalization of bow-tie dendrimers for therapeutic studies.

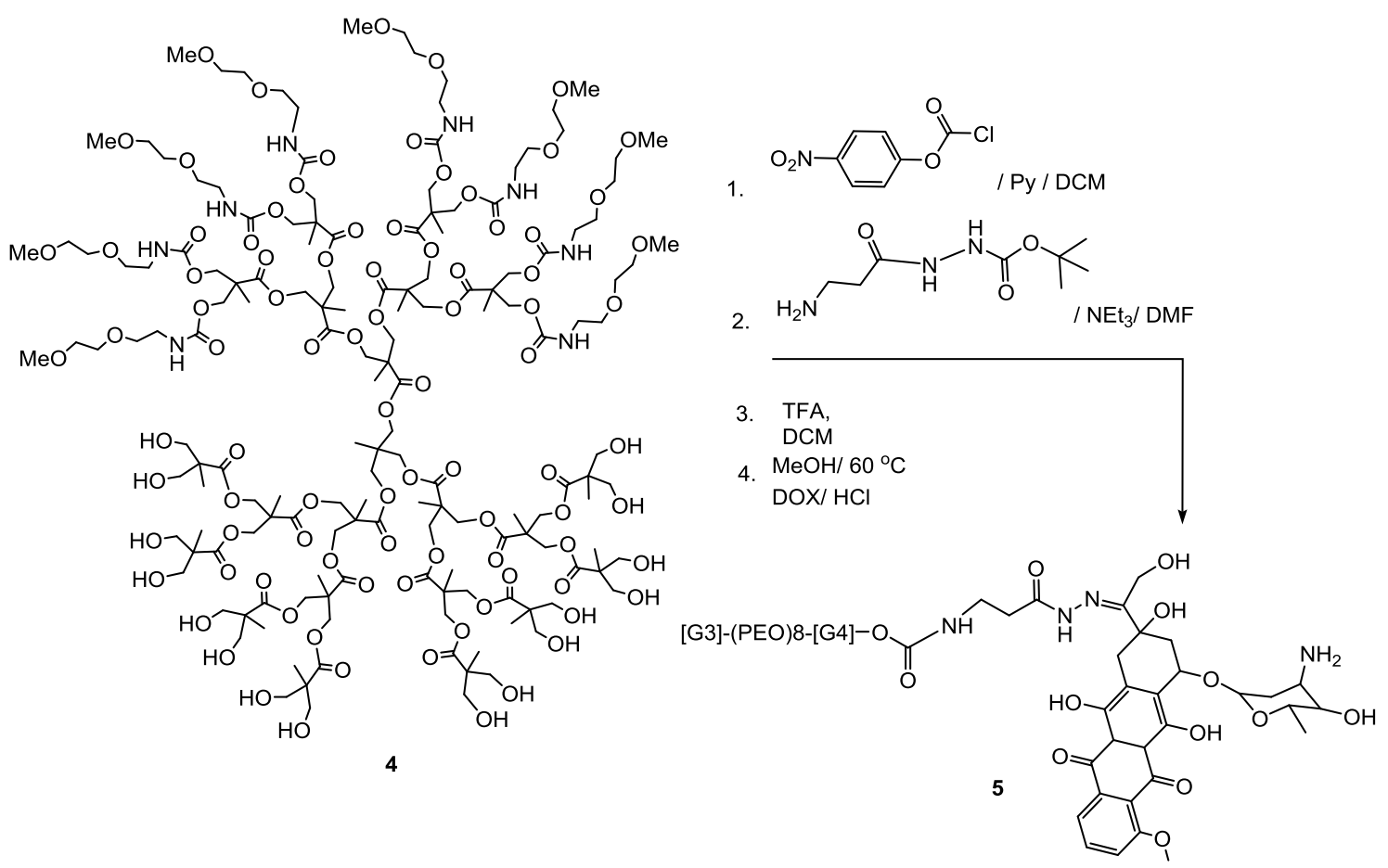

In summary the antitumor effect of doxorubicin (DOX) conjugated to a biodegradable dendrimer was evaluated in mice bearing C-26 colon carcinomas. A bow tie biodegradable polyester dendrimer containing 8-10 wt\% DOX was prepared. The design of the dendrimer carrier optimized blood circulation time through size and molecular architecture, drug loading through multiple attachment sites, solubility through PEGylation, and drug release through the use of $\mathrm{pH}$-sensitive hydrazone linkages. In culture, dendrimer-DOX was $>10$ times less toxic than free DOX toward C-26 colon carcinoma cells after exposure for $72 \mathrm{~h}$. Upon in vivo administration to mice bearing cancerous cells, dendrimer-DOX was eliminated from the serum with a half-life of $16 \mathrm{~h}$, and its tumor uptake was nine fold higher than in vivo administered free DOX at $48 \mathrm{~h}$. In addition, a single in vivo injection of dendrimer-DOX at $20 \mathrm{mg} / \mathrm{kg}$ DOX equivalents 8 days after tumor implantation caused complete tumor regression and $100 \%$ survival of the mice over the 60 days experiment. No cures were achieved in tumor implanted mice treated with free DOX at its maximum tolerated dose $(6 \mathrm{mg} / \mathrm{kg})$, drug-free dendrimer, or dendrimer-DOX in which the DOX was attached by means of a stable carbamate bond. The antitumor effect of dendrimer-DOX is similar to that of an equimolar dose of liposomal DOX (Doxil). There is no doubt that the remarkable antitumor activity of dendrimer-DOX results from the ability of the dendrimer to favorably enhance the pharmacokinetics profiles of attached doxorubicin.

In another study, Namazi and Adeli reported the synthesis and controlled release of biocompatible prodrugs of $\beta$-cyclodextrin linked with PEG-containing Ibuprofen or Indomethacin [155]. The same group also prepared citric acid-polyethylene glycol-citric acid (CPEGC) triblock dendrimers as biocompatible compounds up to the third generation, and investigated them as potential drug-delivery 
systems [156,157]. The preparation of a second-generation dendrimer of this type is shown in Scheme 3. Here, the encapsulation and the controlled release of anti-inflammatory drugs 5-aminosalisylic acid, mefenamic acid, and diclofenac were investigated [157]. Citric acid and poly(ethyleneglycol) (PEG) were selected because of their good water solubility, low toxicity and biocompatibility and these moieties are widely accepted for use in drug formulations. A series of complexes/drugs from the synthesized dendrimers were prepared. It is worthy pointing out that the isolated water-soluble dendrimers were capable of binding and solubilizing non-polar hydrophobic molecules.

Scheme 3. Synthesis of second-generation dendrimer for drug delivery studies [155-157].

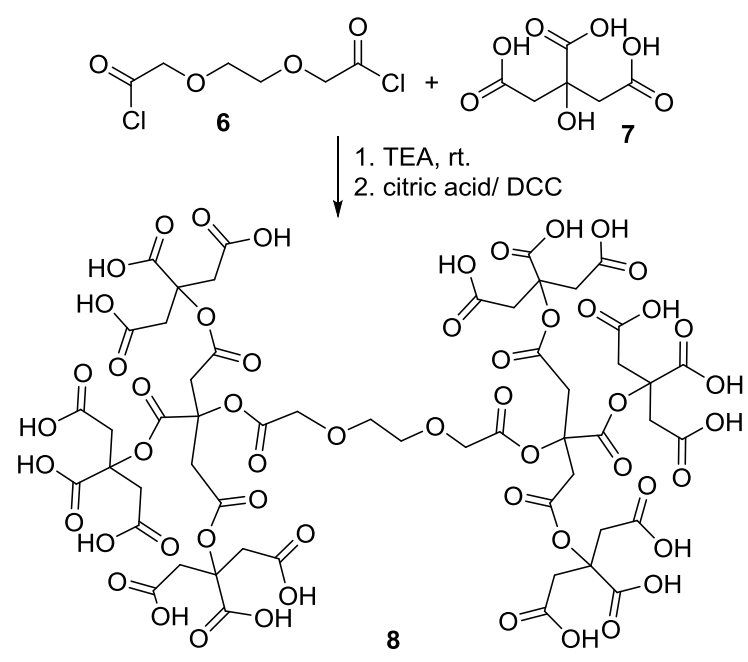

During controlled release investigation, it was noticed that in all cases after approximately $350 \mathrm{~min}$, the release of drugs from the complexes was approximately completed and was changed to a very slow rate [157]. The ability of this type of non-toxic dendrimer to enhance pharmacokinetic profiles of encapsulated drugs is evidence that these dendrimer-drug complexes could be considered as potential drug-delivery systems. This system is a promising polymeric backbone for use as scaffolds in the development of well-defined polymeric drug carriers.

To date clinical experience with neutron capture therapy (NCT) is with the non-radioactive isotope boron-10 (BNCT). The use of other non-radioactive isotopes such as gadolinium has been limited, and to date, it has not been used clinically. BNCT has been evaluated clinically as an alternative to conventional radiation therapy for the treatment of malignant brain tumors and recurrent head and neck cancers [158-161]. Consequently, efficient methods for the delivery of boron-10 to biological tissues have been the subject of longstanding research. However, an obstacle to mainstream application of BNCT for cancer treatment has been the selective delivery of adequate boron concentrations to target tissues [162]. To address this problem, high boron content species such as polyhedral borane clusters, closo- $\left[\mathrm{B}_{10} \mathrm{H}_{10}\right]^{2-}$, closo- $\left[\mathrm{B}_{12} \mathrm{H}_{12}\right]^{2-}$, and the isoelectronic icosahedral family of carboranes, closo- $\mathrm{C}_{2} \mathrm{~B}_{10} \mathrm{H}_{12}$, have attracted significant attention [158]. With this in mind, Adronov and coworkers prepared aliphatic polyester dendrimers based on bis-HMPA that incorporate an easily controllable number of carboranes within the interior of the dendritic structure [163]. Newkome and coworkers had previously reported the production of water-soluble carborane-functionalized dendrimers, involving the reaction of alkyne moieties with decaborane to form ortho-carborane cages within the interior of 
cascade macromolecules [164]. Here [163], It was critical to develop a bifunctional carborane synthon that matches the dual functionality of the bis-HMPA monomer, allowing it to be inserted within the dendrimer synthesis at any generation using traditional esterification reactions. This flexibility in the position of carborane insertion provided control over the boron concentration within a specific dendrimer target compound. Scheme 4 illustrates this synthetic strategy.

Scheme 4. The strategy for incorporation of a carborane synthon into the polyester dendrimer [163].

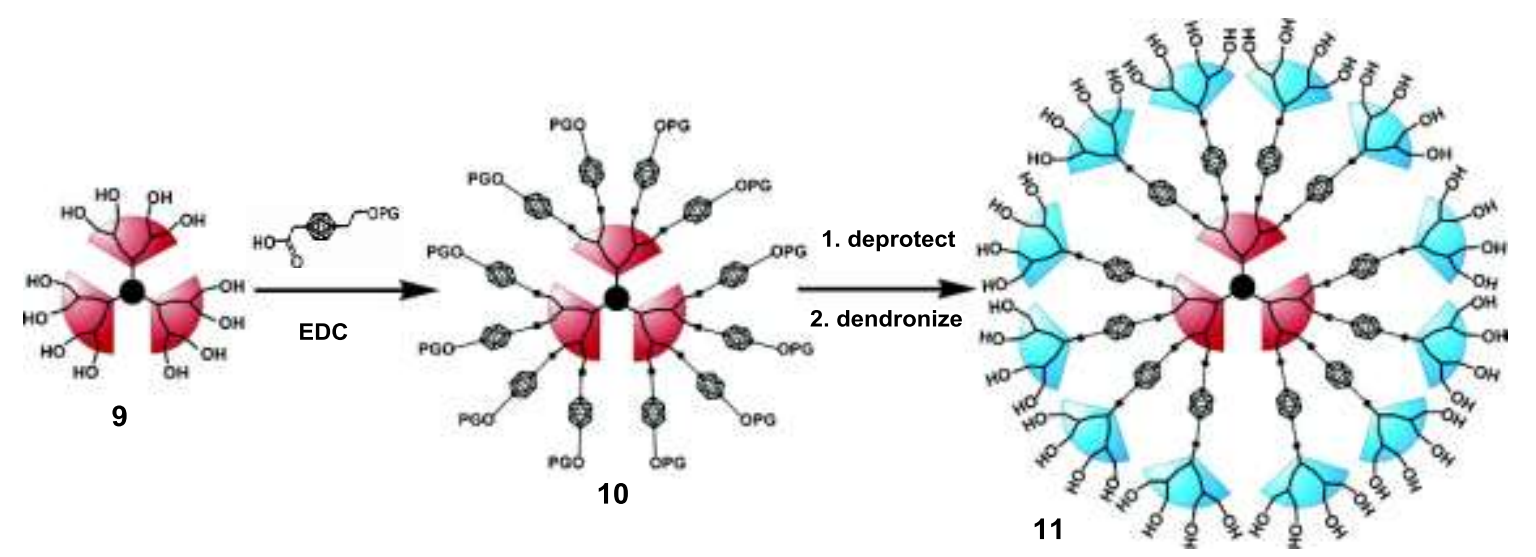

Upon peripheral deprotection to liberate a polyhydroxylated dendrimer exterior, the resulting structures exhibited aqueous solubility as long as a minimum of eight hydroxyl groups per carborane were present. More importantly, irradiation of these materials with thermal neutrons resulted in emission of gamma radiation that is indicative of boron neutron capture events occurring within the carborane-containing dendrimers, indicating that these structures should serve as potential BNCT agents.

A higher percentage of anticancer pharmaceuticals currently in use are natural products and natural product analogues $[165,166]$. Among others, two water soluble analogues of the alkaloid camptothecin are increasingly in clinical use [167-170]. Like many other pharmaceutical drug candidates, camptothecins have suboptimal properties mostly caused by their low water solubility and this resulted in their failure in early clinical trials [167]. Researchers have continued to modify camptothecin analogues in an attempt to circumvent poor water solubility while retaining anticancer potency. However, dose-limiting side effects caused by the water-solubilizing functionalities include severe to life-threatening diarrhea and myelosuppression [171,172]. Consequently, smart delivery vehicles for camptothecins that can reduce side effects while enhancing potency are of particular interest [23,74,173-175]. The work of Grinstaff and coworkers using polyester dendrimers represents an interesting example [101]. Here, a biocompatible polyester dendrimer made up of the natural metabolites, glycerol and succinic acid, was prepared for the encapsulation of the antitumor camptothecins (10-hydroxycamptothecin (10HCPT) and 7-butyl-10-aminocamptothecin (BACPT)). Figure 3 illustrates an example of this type of polyester dendrimer and the encapsulation of 10-hydroxycamptothecin in the dendritic interior [101]. Cytotoxicity studies of the dendrimer-drug complex toward four different human cancer cell lines, human breast adenocarcinoma (MCF-7), colorectal adenocarcinoma (HT-29), non-small cell lung carcinoma (NCI-H460), and glioblastoma (SF-268), were performed. The results with 10HCPT in HT-29 cells indicated that the dendrimer-10HCPT assembly had a 3.5-fold increase in potency relative 
to DMSO-dissolved 10HCPT and a 4.1-fold increase in comparison to DMSO-dissolved 10HCPT stock with subsequent dilutions made in water.

Figure 3. Encapsulation of antitumor camptothecin [101].

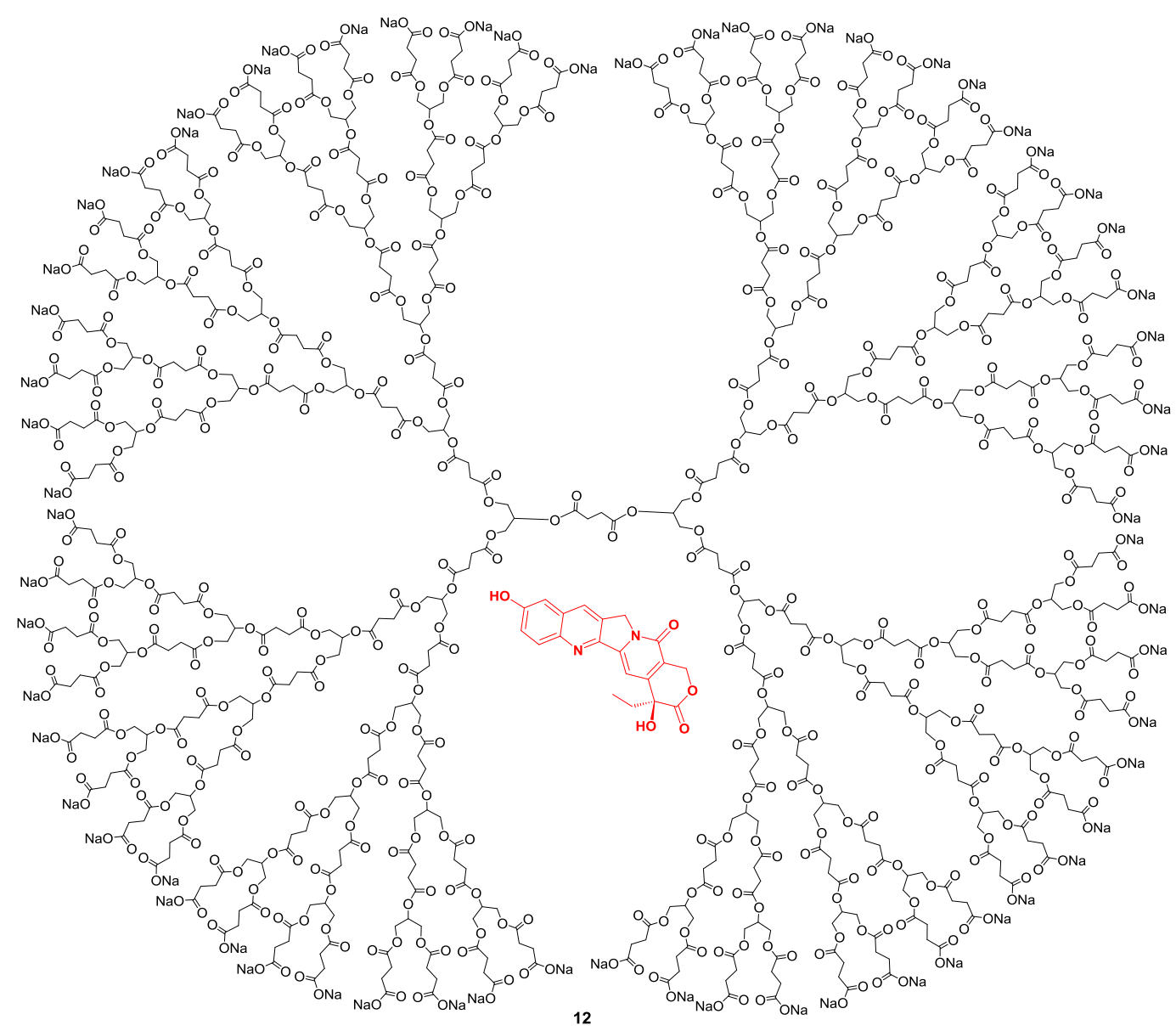

To determine whether the increase in anticancer activity conferred by dendrimer-encapsulated 10HCPT was observed with other cell lines, 10HCPT dissolved in DMSO and the dendrimer-encapsulated 10HCPT formulations were compared in a diverse human cancer cell panel consisting of the MCF-7 human breast adenocarcinoma, the NCIH460 human large cell lung carcinoma, and the SF-268 human astrocytoma. Interestingly, the dendrimer-encapsulated 10HCPT exhibited an improved degree of potency relative to the DMSO-dissolved drug in each cell line. Specifically, the $\mathrm{IC}_{50}$ values for the DMSO-dissolved 10HCPT compared with the dendrimer-encapsulated 10HCPT was reduced from 72.0 to $10.1 \mathrm{nmol} / \mathrm{L}$ for the MCF-7-treated cells, from 32.4 to $16.7 \mathrm{nmol} / \mathrm{L}$ for the NCI-460-treated cells, and from 13.1 to $4.6 \mathrm{nmol} / \mathrm{L}$ for the SF-268-treated cells.

The more hydrophobic camptothecin analogue, BACPT, which possesses a 10-fold greater cytotoxic activity in most tumor cell lines when compared to 10HCPT, was also examined. The dendrimer encapsulation process allowed an enhanced aqueous solubility to the BACPT of $440 \mu \mathrm{mol} / \mathrm{L}$. HCPT). Even though the dendrimer encapsulation afforded no improvement on the cytotoxicity toward HT-29 cells relative to DMSO-dissolved drug, the dendrimer-encapsulated BACPT exhibited an improved degree of potency relative to the DMSO-dissolved agent in each of the other cell lines. Comparing the DMSO-dissolved BACPT to the dendrimer-encapsulated BACPT, the $\mathrm{IC}_{50}$ values were reduced from 
26.7 to $8.3 \mathrm{nmol} / \mathrm{L}$ for the MCF-7-treated cells, from 1.2 to $0.6 \mathrm{nmol} / \mathrm{L}$ for the NCI-H460-treated cells, and from 6.6 to $1.2 \mathrm{nmol} / \mathrm{L}$ for the SF-268-treated cells. The results in this work [101] strongly suggest that these types of polyester dendrimers may be of significant utility in improving the aqueous solubility of other camptothecin analogues as well as other hydrophobic drugs with suboptimal pharmacokinetics.

The discovery and development of new and potent drugs is a time-consuming and costly process. It may take up to 15 years to develop a new drug, mostly because of lengthy clinical trials [176]. A more economical and viable strategy is to devise effective delivery systems for drugs that have failed to provide optimum therapeutic benefit since controlled release of a drug at a specific target can significantly improve the effectiveness of a drug and thereby increase the therapeutic benefit [177]. With this in mind, Hildgen and coworkers synthesized novel polyester-co-polyether (PEPE) dendrimers having a hydrophilic core [102]. The core was synthesized using the biocompatible moieties, butanetetracarboxylic acid and aspartic acid, and the dendrons were derived from PEG, dihydroxybenzoic acid or gallic acid, and PEG monomethacrylate. Dendrimers were then obtained by coupling the dendrons to the core [102].

A second generation dendrimer of this type is shown in Figure 4. This type of dendrimer demonstrated good ability to encapsulate the guest molecule with loadings of 15.80 and $6.47 \%$ w/w for rhodamine and $\beta$-carotene respectively. The release of the encapsulated compounds was found to be slow and sustained, suggesting that these dendrimers can serve as potential drug delivery systems [102].

Figure 4. A novel second-generation dendrimer with a hydrophilic interior [102]. The letters $\mathrm{m}$ and $\mathrm{n}$ indicate the number of ethylene glycol repeats.

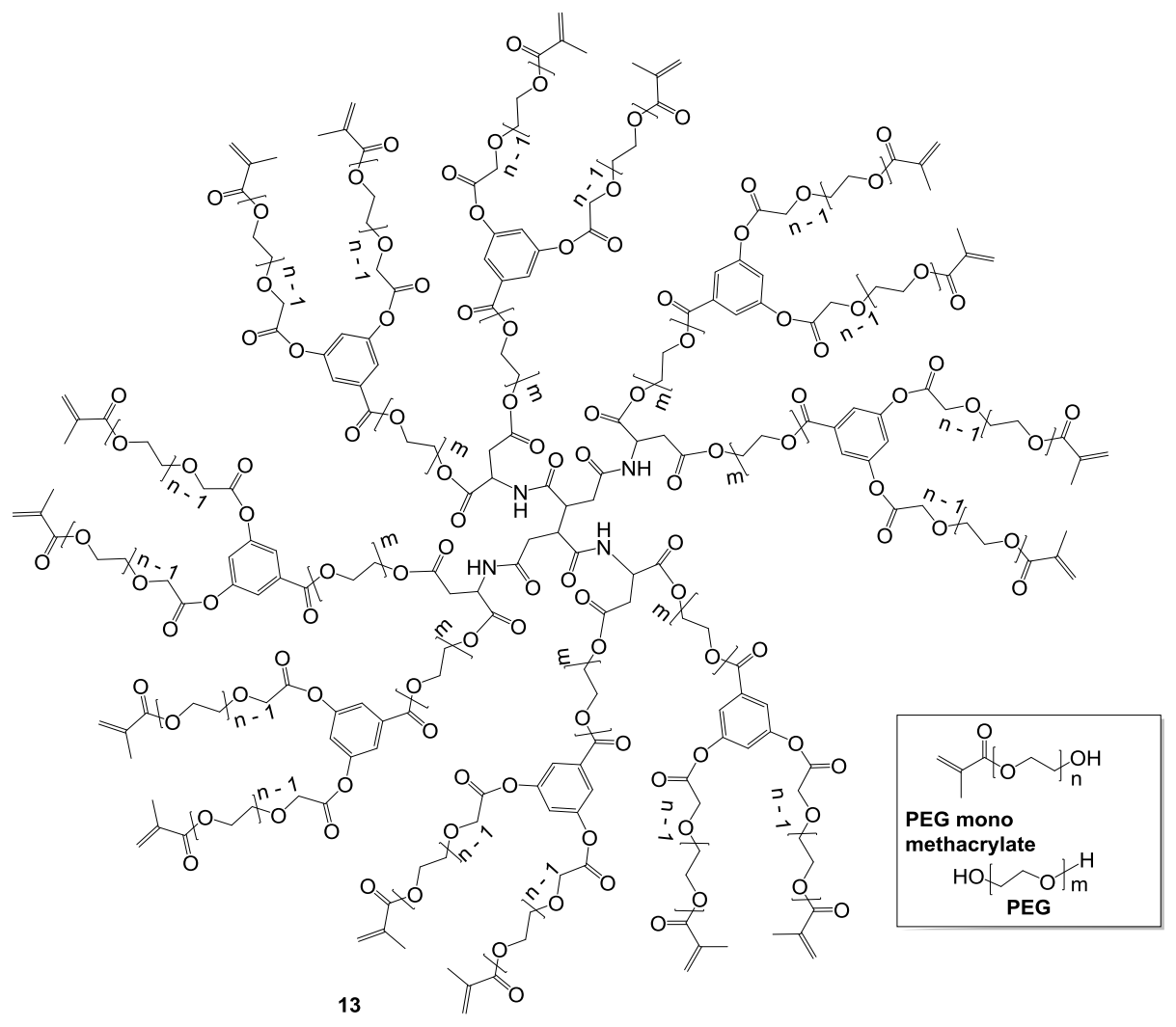


Around the same time, the same authors investigated the influence of molecular architecture of PEPE dendrimers on the encapsulation and release of methotrexate [178]. In this study, effects of alterations in the chemical structure of PEPE dendrimers on the encapsulation and release of methotrexate was investigated. A series of PEPE dendrimers of different architecture were synthesized [178]. The biocompatibility of this type of dendrimers was evaluated in vitro by assessing their cytotoxicity on RAW 264.7 cells using the lactate dehydrogenase assay. Dendrimers caused no cell death even at a concentration of $250 \mathrm{mg} / \mathrm{mL}$, suggesting that they are acceptable for pharmaceutical applications. They also showed good capacity to encapsulate methotrexate, with loading as high as $24.5 \% \mathrm{w} / \mathrm{w}$. Increasing in the number of branches and the size of internal voids were shown to enhance the encapsulation. On the other hand, the absence of aromatic rings as branching units drastically reduced the loading capacity. Using spectroscopic studies, it was illustrated that physical entrapment, weak hydrogen bonding and hydrophobic interactions were the mechanisms of encapsulation. The release of methotrexate included a burst release in the first $6 \mathrm{~h}$ followed by a slower release over a period of 50 or $168 \mathrm{~h}$. Increasing the number of branches decreased the initial burst release and in contrast, the absence of aromatic rings in the dendritic structure resulted in a very rapid release [178]. Thus, this new macromolecular system exhibits promising characteristics for the development of new polymeric drug carriers.

The transformation of linear polymers into dendronized polymers is another avenue of polymer synthesis that has received attention. When monodisperse dendrons are attached to a linear polymer backbone, the resulting dendronized polymers have new properties and new potential applications, resulting from the almost dendritic nature of the new system. In this regard, Fréchet, Szoka and coworkers [179] synthesized rigid-rod dendronized linear polymers consisting of a poly(4-hydroxystyrene) backbone and fourth generation polyester dendrons [179]. Figure 5 shows a schematic representation for this type of dendronized polymers. Both in vitro and in vivo evaluations of the polymers were then carried out to determine their suitability as drug delivery vehicles. Cytotoxicity assays indicated that these polymers are well tolerated by cells in vitro. Detailed biodistribution studies of the polymers in both non-tumored and tumored mice revealed that as for random coil linear polymers, renal clearance was a function of polymer size [179]. High accumulation in organs of the reticuloendothelial system was exhibited by a dendronized polymer with a very high molecular weight $(M \mathrm{n}=1740 \mathrm{kDa})$, but was not as significant for smaller polymers with $M \mathrm{n}=67 \mathrm{kDa}$ and $M \mathrm{n}=251 \mathrm{kDa}$. Even though polymers with degradable backbones are more suited to prevent long-term accumulation [180], these highly functionalizable, nontoxic, dendronized polymers represent a promising new scaffold for polymeric systems with pharmacokinetic properties appropriate for use as drug carriers.

Paclitaxel is a mitotic inhibitor used in cancer chemotherapy which has shown substantial clinical efficacy for various cancer types including ovarian, breast, colon, head and neck, and non-small cell lung cancers $[181,182]$. Due to its poor solubility however, paclitaxel is usually formulated as a $1: 1$ mixture of Cremophor EL and ethanol, which is diluted in normal saline or dextrose solution to a final paclitaxel concentration of $5 \%$ for administration [182]. This formulation has severe side effects caused by its Cremophor EL and the organic solvent [183,184]. Consequently, several attempts have been made to increase the poor paclitaxel solubility $(0.3 \mathrm{mg} / \mathrm{mL})$ using various formulations or prodrug conjugates [185-193]. Kontoyianni, Sideratou and coworkers [194] successfully functionalized commercially available hyperbranched aliphatic polyester Boltorn H40 [63,195,196] with PEG chains to afford a novel water-soluble BH40-PEG polymer exhibiting unimolecular micellar properties 
appropriate for application as a drug delivery system [194]. After paclitaxel was encapsulated, the solubility of the anticancer drug was enhanced by a factor of $35,110,230$, and 355 in aqueous solutions of BH40-PEG with concentrations of 10,30,60, and $90 \mathrm{mg} / \mathrm{mL}$, respectively. After an initial slow release during the first 100 minutes, more than $50 \%$ of the drug was released at a steady rate that is desirable in controlled release systems and release was almost complete within $10 \mathrm{~h}$. The toxicity of BH40-PEG was assessed in vitro with A549 human lung carcinoma cells and found to be nontoxic for $3 \mathrm{~h}$ incubation up to a $1.75 \mathrm{mg} / \mathrm{mL}$ concentration. The anticancer drug was also found to efficiently internalize in cells, primarily in the absence of foetal bovine serum, while confocal microscopy revealed the preferential localization of the drug compound in cell nuclei [194]. This is another example of how polyester based macromolecules can enhance the pharmacokinetic profiles of attached or encapsulated drugs.

Figure 5. A representation of a dendronized linear polymer and the structure of fourth-generation dendronized poly(4-hydroxystyrene) [179].

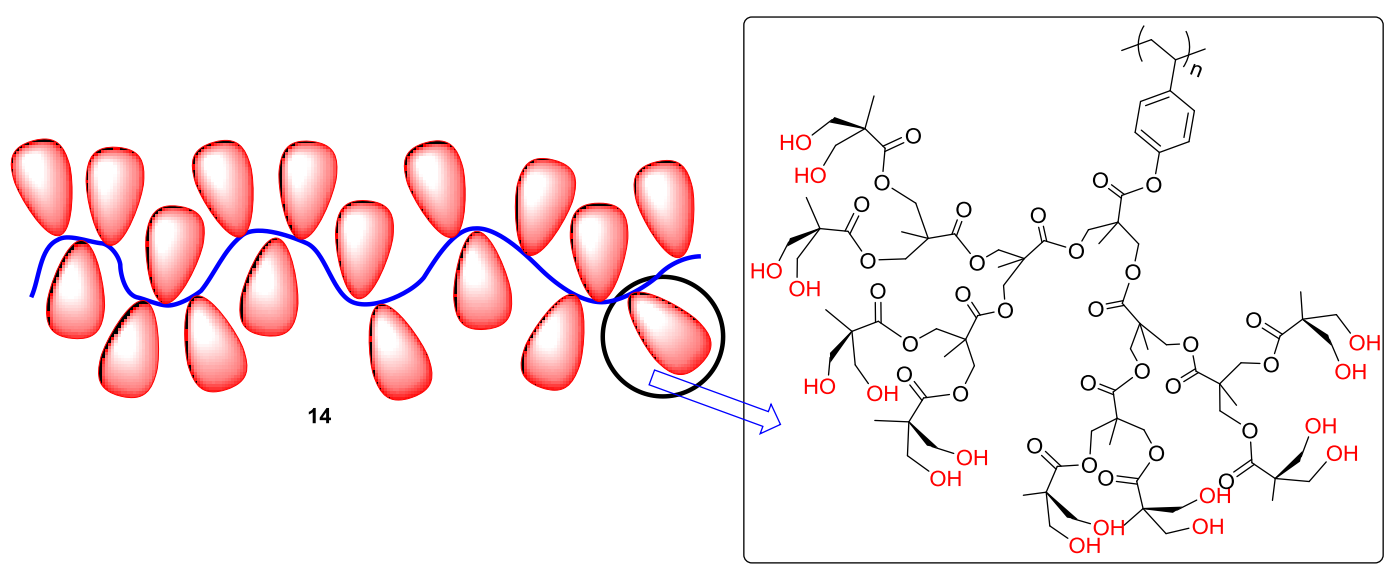

Other recent attempts to improve paclitaxel pharmacokinetic profiles include the work of Kissel and coworkers [197]. The authors aimed to formulate nanoparticles from three different hyperbranched polymers, namely unmodified dendritic polyester (Boltorn H40), a lipophilic, fatty acid modified dendritic polymer (Boltorn U3000), and an amphiphilic dendritic polymer (Boltorn W3000) (see Figure 6) for drug delivery of paclitaxel and to investigate their properties. Boltorn series hyperbranched aliphatic polyesters have great potential for applications in the biomedical field [198] due to their low toxicity, immunogenicity [56], and biodegradability [63]. Here [197], a solvent displacement method allowed preparation of nanoparticles from all three hyperbranched polymers. The lipophilic Boltorn U3000 formed the biggest nanoparticles while the amphiphilic Boltorn W3000 formed the smallest ones. Degradation profiles were investigated by short time $\mathrm{pH}$-stat titration. Boltorn H40 showed a faster degradation rate than the fatty acid containing polymers. For Boltorn $\mathrm{H} 40$, degradation rate was also investigated in longer term mass loss studies resulting in $30 \%$ degradation during 3 weeks. Cytotoxicity studies for the nanoparticles revealed low cytotoxicity for all three polymers. All three types of nanoparticles were then loaded with paclitaxel and their release profiles were studied. Sizes and zeta potentials remained stable after loading and did not change significantly. Boltorn U3000 and W3000 represent interesting candidates for drug delivery application due to their high loading efficiency. 
Figure 6. Schematic illustration of the Boltorn series: (15) Boltorn H40; (16) Boltorn U3000; and (17) Boltorn W3000 [197].

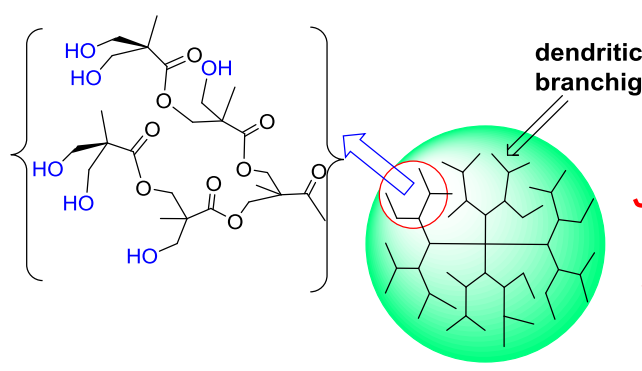

15

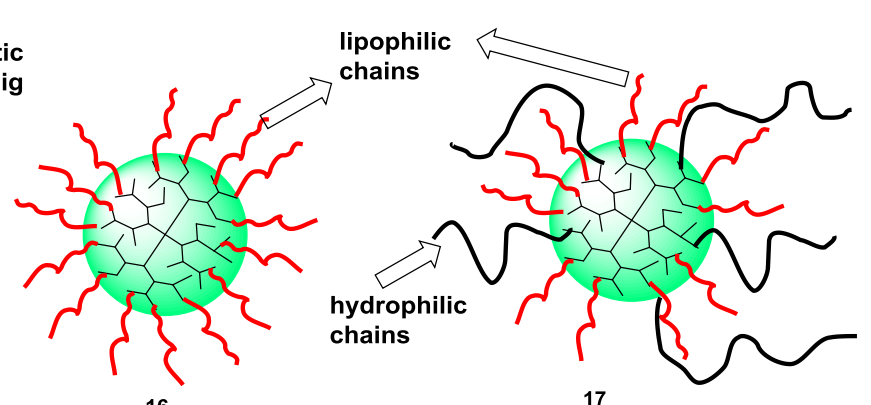

16

17

The work of Wang and $\mathrm{Xu}$ [199] also illustrates the potential of Boltorn series hyperbranched aliphatic polyesters as drug delivery systems. Here, a commercially available dendrimer-like hyperbranched polymer was used as a starting material in the development of a facile synthetic route for the construction of a folic acid-based multivalent targeted drug delivery system [199]. In this system, fluorescein was incorporated to act as the imaging reagent, folic acid as the targeting reagent, and methotrexate as the chemotherapeutic reagent. This method used the unpaired hydroxyls on the Boltorn dendrimer to conjugate with fluorescein, thereby making good use of the defect in the polyester. Folic acid, methotrexate, and fluorescein were all successfully attached to the polyester as illustrated in Figure 7. Even though the application of this multivalent targeted drug delivery system in clinical drugs was not reported, this system exemplifies a potentially inexpensive and well-defined multivalent targeted drug delivery carrier [199].

Figure 7. The synthesis of the folic acid-based targeted drug delivery system [199].
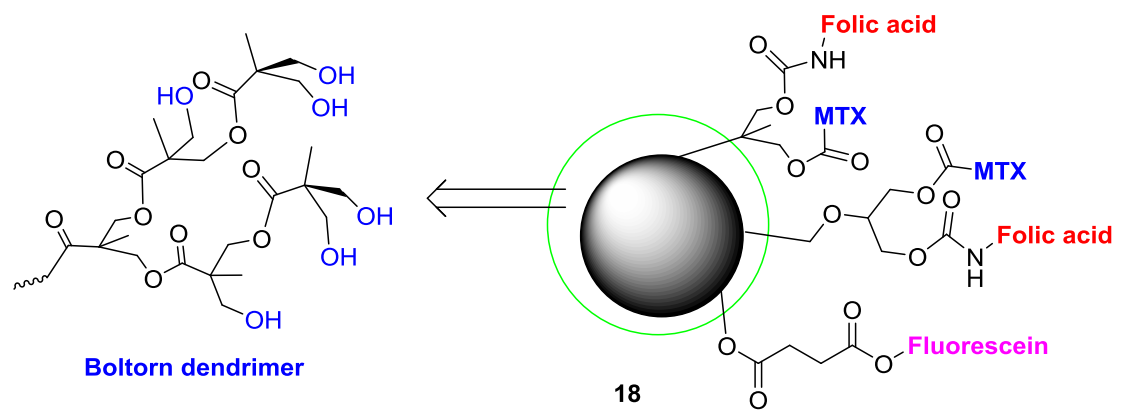

Recently, Nyström and coworkers modified Boltorn H30 and H40 using an average of 5 PEG chains prior to the encapsulation of DOX for delivery to breast cancer cells [200]. DOX-loaded H30-PEG10k nanoparticles exhibited controlled release over longer periods of time and flow cytometry and confocal scanning laser microscopy studies indicated that the cancer cells could internalize the DOX-loaded H30-PEG10k nanoparticles. This contributed to the sustained drug release, and induced more apoptosis than free DOX. These findings are further indications that Boltorn based nanoparticles may offer an alternative strategy for delivering drugs to cancer cells.

The various types of delivery vehicles studied to date, including linear polymers, micellar assemblies, liposomes, and polymersomes, do not possess all the desired design features [201] one would want in an efficient drug carrier. Features such as a long blood circulation time, high tumor 
accumulation, high drug loading capacity, low toxicity, low polydispersity index, and simple preparation are necessary for a suitable drug carrier. Considering the above criteria, PEGylated dendrimers constitute an attractive option, because their size and degree of branching can be precisely controlled and they possess multiple functional appendages for the attachment of both drugs and solubilizing groups.

To minimize the hydrolytic susceptibility of the ester bond during synthesis of drug conjugates, Fréchet, Szoka and coworkers reported an elegant synthesis that combines the biocompatibility of bis-HMPA dendrimers with the robustness of polyamide dendrimers, yielding a hybrid scaffold capable of translation into clinical studies [98]. A drug loaded PEGylated ester-amide dendrimer is shown in Figure 8. The biodistribution of the ester-amide dendrimer was determined in C26 tumored female $\mathrm{Balb} / \mathrm{C}$ mice. Mice were injected with $8 \mathrm{mg}$ Dox eq/kg, formulated as Doxil or compound 19. After $48 \mathrm{~h}$, Dox had significantly accumulated within the tumor compared to insignificant amount in vital organs. This observation is important because lowering Dox accumulation in the vital organs is important for reducing toxicity, while uptake by tumor tissue must be maintained to promote treatment efficacy.

Figure 8. A drug (DOX) loaded PEGylated ester-amide dendrimer [98].

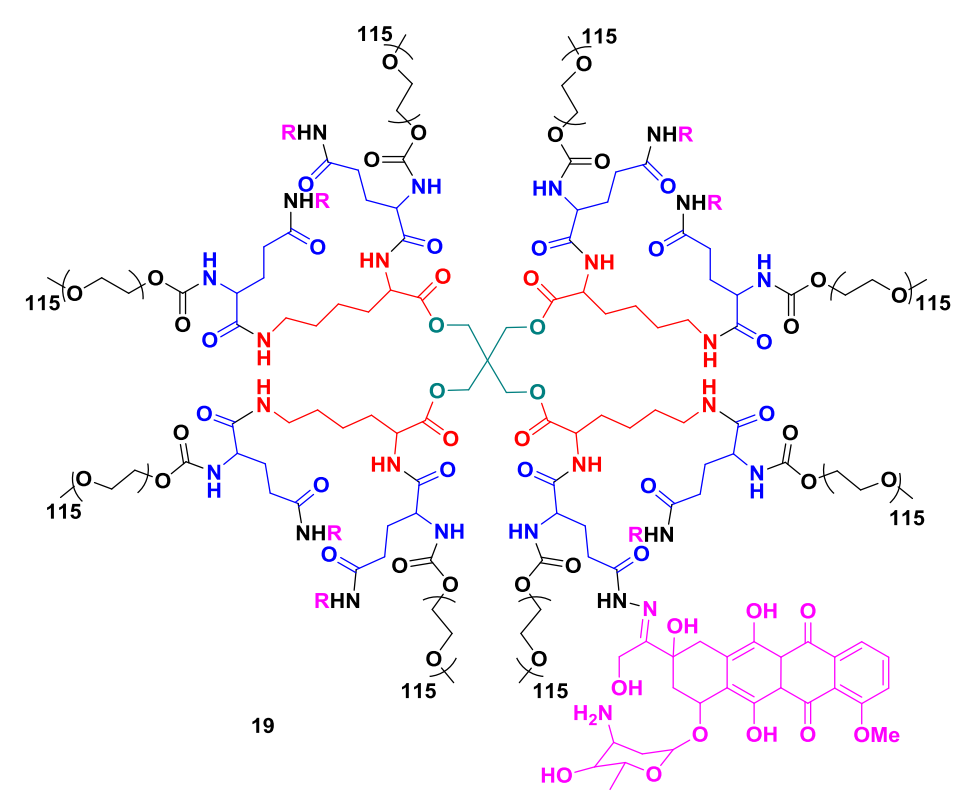

For therapeutic studies, a dose-response experiment was performed in C26 tumored Balb/C mice, and four treatment groups were investigated, Doxil (20 mg Dox $/ \mathrm{kg})$ and compound 19 (10, 15, and $20 \mathrm{mg}$ Dox/kg). Dose-dependent survival was observed and all three groups treated with loaded PEGylated ester-amide dendrimer 19 showed significant tumor growth delay and prolonged survival. Mice treated with compound 19 at $20 \mathrm{mg}$ Dox/kg had 9 out of 10 mice tumor free at the end of 60 days. The results in this study and earlier studies [57] confirm that Dox-loaded PEGylated dendrimer carriers are as effective as Doxil against the C26 tumor model.

In another recent study, Malkoch, Fadeel and coworkers elegantly evaluated the biocompatibility of a library of aliphatic polyester dendrimers based on bis-HMPA [59]. In addition, dendrimers with two different chemical surfaces (neutral with hydroxyl end group and anionic with carboxylic end group) and dendrons corresponding to the structural fragments of the dendrimers were also evaluated. 
Commercially available PAMAM dendrimers with cationic (amine) or neutral (hydroxyl) end groups were also included for comparison. In vitro studies were conducted in human cervical cancer and acute monocytic leukemia cells differentiated into macrophage-like cells as well as in primary human monocyte-derived macrophages. The entire hydroxyl functional bis-HMPA dendrimer library demonstrated excellent biocompatibility, whereas the cationic, but not the neutral PAMAM exerted dose-dependent cytotoxicity in cell lines and primary macrophages. Studies to evaluate material stability as a function of $\mathrm{pH}$, temperature, and time, demonstrated that the stability of the 4th generation hydroxyl functional bis-HMPA dendrimer increased at acidic $\mathrm{pH}$. This is further indication that bis-HMPA polyester dendrimers are degradable and non-cytotoxic.

Polymeric micelles can be formed in solution only above the critical micelle concentration. However, micelles formed from amphiphilic block copolymers have attracted attention in drug delivery because of their ability to decrease unwanted side effects, prolong the circulation time, and reduce uptake by the reticuloendothelial system (RES) [202-205]. On the other hand, micelles injected into the body are usually subjected to severe dilution and this normally leads to their dissociation and a rapid release of physically encapsulated drugs. Consequently, their effectiveness in drug delivery and their in vivo application are considerably reduced [206]. The use of amphiphilic polymeric unimolecular micelles can help to eliminate problems associated with the dissociation and the large sizes of polymeric micelles. Dendrimer-like star polymers composed of a hydrophobic star polymer core and a hydrophilic dendron shell, have a potential to deliver drugs more effectively via appropriate structure-tuning. Wang and coworkers synthesized well-defined folate-functionalized dendrimer-like star polymers, by combining living ring-opening polymerization (ROP) of L-lactide and dendrimer synthesis [207,208]. Here [207,208], a poly(L-lactide) star polymer was selected as the hydrophobic core and non-toxic biodegradable dendrons based on bis-HMPA were used as the shell [208,209]. Surface functionalization using carboxylic acid groups allowed further conjugation with PEG oligomers for water solubility enhancement. These dendrimer-like star polymer nanoparticles were then functionalized further with folic acid because it is known that folic acid is non-immunogenic and has a strong binding affinity to the folate receptors, which are overexpressed on the surface of many human tumor cells [210-212]. Scheme 5 shows the functionalization of this type of dendrimer-like star polymers using folic acid and the fluorescent probe, Hilyte488. Hilyte488 was attached to the G1-g3-FA conjugate to form G1-g3-FA-Hiyte488. UV-vis spectroscopy was employed to determine the number of Hilyte488 units incorporated per G1-g3-FA. In vitro results showed that FA-functionalized and anticancer drug-loaded degradable dendrimer-like star polymer (DLSP) could specifically target and kill human KB cells [209].

This folate-functionalized degradable amphiphilic dendrimer-like star polymer (FA-DLSP) hybrid formed unimolecular micelles in the aqueous solution with a mean particle size of about $15 \mathrm{~nm}$ as determined by dynamic light scattering and transmission electron microscopy. To study the feasibility of the dendrimer-like micelles as potential nanocarriers for targeted drug delivery, the anticancer agent DOX was encapsulated in the hydrophobic core, and the loading content was determined by UV/VIS analysis to be $4 \%$ by weight. The DOX loaded dendrimer-like micelles demonstrated a sustained release of DOX due to the hydrophobic interaction between the polymer core and the drug molecules [207]. The hydrolytic degradation in vitro was monitored by weight loss and proton nuclear magnetic resonance spectroscopy to gain insight into the degradation mechanism of the micelles. It 
was found that the degradation was $\mathrm{pH}$-dependent and started from the hydrophilic shell and moved gradually to the hydrophobic core. Flow cytometry and confocal microscope studies revealed that the cellular binding of the FA-DLSP hybrid against human KB cells with overexpressed folate-receptors was about twice that of the neat DLSP (without FA). The in vitro cellular cytotoxicity indicated that the FA-DLSP micelles (without DOX) had good biocompatibility with human KB cells, whereas DOX loaded micelles exhibited a similar degree of cytotoxicity against human KB cells as that of free DOX. These results clearly show that this type of dendrimer-like unimolecular micelles are a promising nanosize anticancer drug delivery system with excellent targeting properties [207].

Scheme 5. Functionalization of dendrimer-like poly(L-lactide) (PLLA) star polymer for drug delivery studies [209].

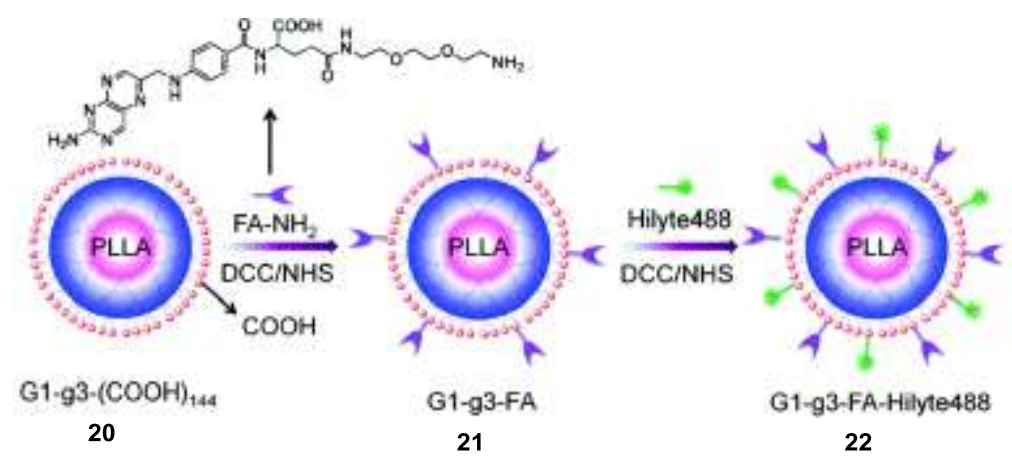

Polymer vesicles commonly referred to as polymersomes have recently received significant attention for biological applications [213-221]. Polymersomes can be readily accessed from a wide range of block copolymers and they typically exhibit much lower critical aggregation concentrations and enhanced thermodynamic and kinetic stabilities [222,223]. Recently, Gillies and coworkers exploited the multivalent and multifunctional capabilities of polymersomes in a dendritic sialopolymersome system designed to interact with the influenza virus at two different stages in the infection process [103]. First, the sialic acid $\mathrm{N}$-acetylneuraminic acid (Neu5Ac) was conjugated to the polymersome surface in order to inhibit the binding of viral hemagglutinin to sialic acids on host cells, thus preventing viral entry. Second, the neuraminidase inhibitor zanamivir was encapsulated into the polymersome core in order to prevent the release of progeny virus from the host cells, thus inhibiting viral replication. With the aim of maximizing multivalent effects at the polymersome surface, polyester dendrons functionalized with Neu5Ac were synthesized and conjugated to polymersomes. The binding of the resulting dendritic sialopolymersomes to Limax flavus agglutinin was studied and compared to the sialodendron and a monovalent Neu5Ac derivative using an enzyme-linked lectin inhibition assay. The results of this study revealed that while the sialodendron exhibited a 17-fold enhancement (per sialoside) relative to the small molecule, the dendritic sialopolymersomes resulted in an almost 2000-fold enhancement in binding affinity. It was also found that encapsulation of zanamivir into the dendritic sialopolymersomes could be performed with the same efficiency as for naked polymersomes to provide a drug loading of about $35 \mathrm{wt} \%$. Drug release rates were similar for both systems with sustained release over a period of 4 days. The results described in this paper indicate that multifunctional polymersome systems can be used for the interaction with and inhibition of influenza viruses [103]. 
Polyester dendrimers are often synthesized by repeated esterification of bis-HMPA dendron followed by deprotection. This synthetic strategy is straightforward, but when the protection/deprotection reactions are incomplete, defects and thus polydispersity are introduced. Shen and coworkers [19] suggest that aliphatic polyester dendrimers without heterocyclics have better biocompatibility and biodegradability for translational nanocarriers. Using the highly efficient thiol/acrylate Michael addition reactions, a strategy for the synthesis of bis-HMPA-based dendrimers without any protection/deprotection steps was developed. Scheme 6 shows the preparation of a dendrimer bearing 128 terminal hydroxyl groups in five steps. To investigate the potential of this type of dendrimers as drug carriers, G5-128 $\mathrm{OH}$ was pegylated to obtain a water-soluble biocompatible dendrimer capable of encapsulation and controlled release of a hydrophobic anticancer drug, doxorubicin. The esterification of G5-128 $8_{\mathrm{OH}}$ using PEG2k-COOH and the loading of G5-PEG with DOX is shown in Scheme 7.

Scheme 6. Efficient synthesis of a fifth generation aliphatic polyester dendrimer [19].
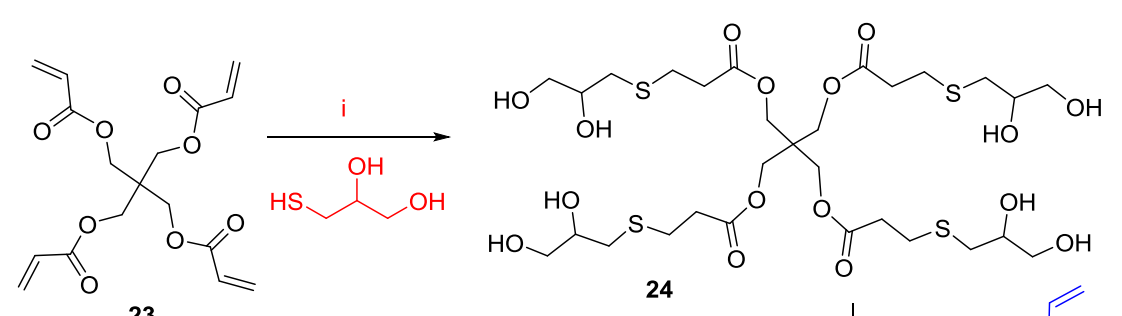

24

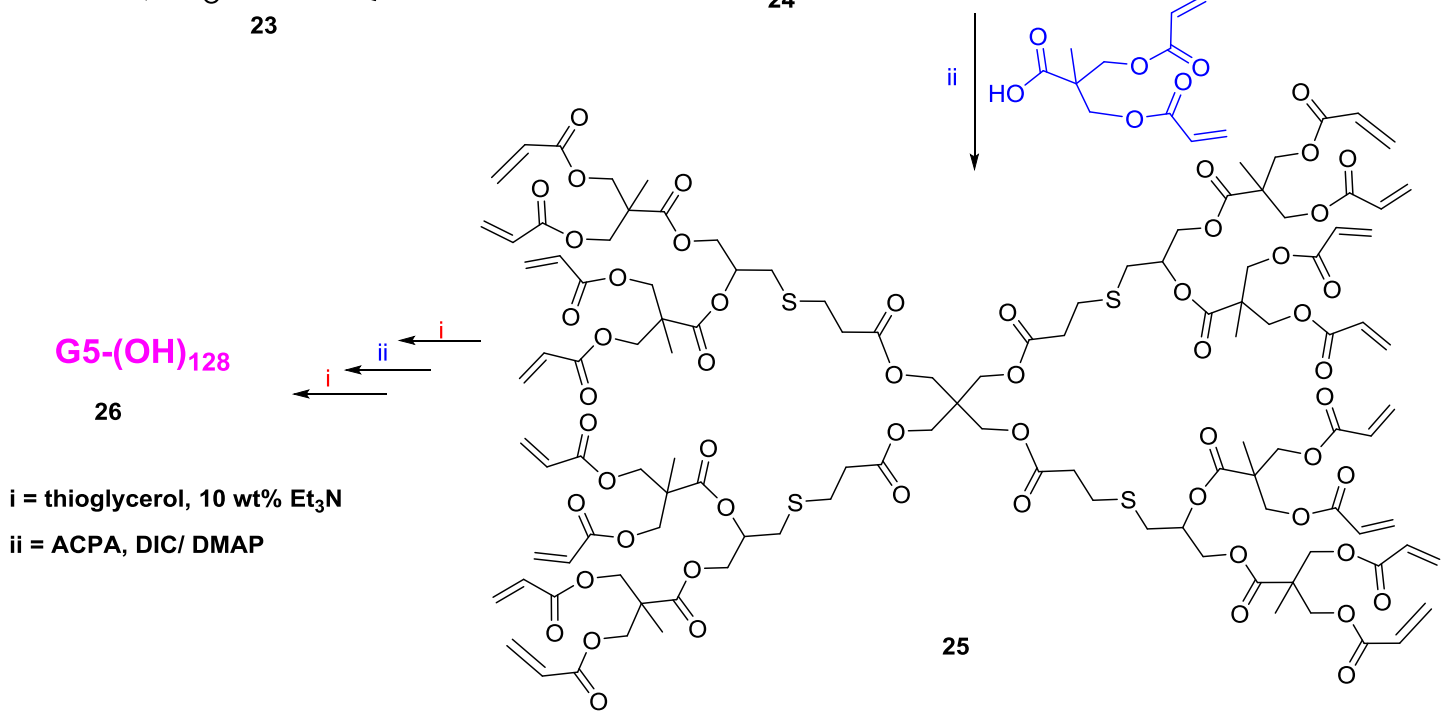

Evaluation of the G5-PEG/ DOX complex revealed that DOX could be released with a slight burst at $\mathrm{pH} 7.4$ and $37{ }^{\circ} \mathrm{C}$ followed by a very slow release. About $40 \%$ of the DOX was released in $24 \mathrm{~h}$ and less than $60 \%$ in $100 \mathrm{~h}$. This sustained release is an improvement and is in contrast to the usually severe burst release of most micellar drug carriers [224,225]. DOX release was greatly enhanced at acidic $\mathrm{pH}$. Upon evaluation of the cytotoxicity of free DOX, G5-PEG/ DOX (15.2 wt\% DOX), and G5-PEG to ovarian cancer cells, it was found that G5-PEG was not toxic even at high doses. The $\mathrm{IC}_{50}$ of the DOX in the G5-PEG/ DOX to SKOV-3 ovarian cancer cells was $0.085 \mu \mathrm{g} / \mathrm{mL}$, not significant different from that of free DOX $(0.056 \mu \mathrm{g} / \mathrm{mL})$. Further evaluations of this type of dendrimers as drug carriers are currently underway [19]. 
Scheme 7. Preparation of G5-PEG and its loading with DOX [19].

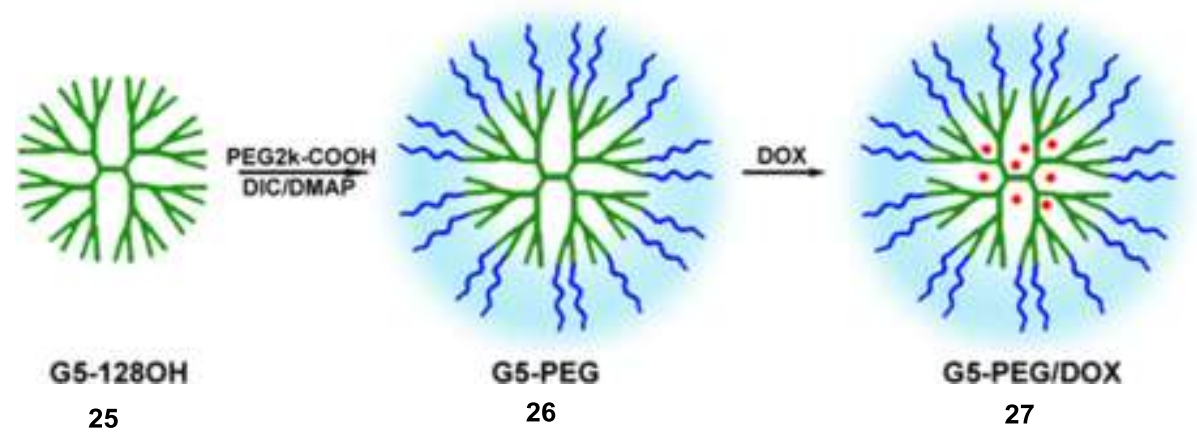

\section{Conclusions}

Various types of delivery vehicles including linear polymers, micellar assemblies, liposomes, polymersomes, and dendrimers have been studied in an effort to identify an ideal drug carrier. The use of dendrimers as drug carriers by encapsulating hydrophobic drugs is an attractive method for delivering highly active pharmaceutical compounds that may not be in clinical use due to their limited water solubility and suboptimal pharmacokinetics. There has been a substantial interest in the area of polyester dendrimers as potential drug delivery carriers because of their relatively easy preparation, biodegradability, and biocompatibility. Encapsulation and conjugation of drugs with polyester dendrimers have shown immense employment for the improvement of pharmacokinetic profiles of hydrophobic and labile drugs. In vitro and in vivo studies have shown that, in contrast to other dendrimers and polymers, the polyester dendrimer scaffold is hydrolytically degradable and less toxic and does not accumulate in vital organs. Activity in the evaluation of polyester dendrimers as drug carriers has intensified over the last few years and the trend is expected to continue.

\section{Acknowledgments}

We thank Natural Sciences and Engineering Research Council of Canada (NSERC) for support.

\section{Conflicts of Interest}

The authors declare no conflict of interest.

\section{References}

1. Ringsdorf, H. Structure and properties of pharmacologically active polymers. J. Polym. Sci. Pol. Sym. 1975, 51, 135-153.

2. Bader, H.; Ringsdorf, H.; Schmidt, B. Water soluble polymers in medicine. Angew. Makromol. Chem. 1984, 123, 457-485.

3. Kopeček, J. Soluble biomedical polymers. Polym. Med. 1977, 7, 191-221.

4. Kopeček, J.; Kopeckova, P.; Minko, T.; Lu, Z.R. HPMA copolymer-anticancer drug conjugates: Design, activity, and mechanism of action. Eur. J. Pharmaceut. Biopharmaceut. 2000, 50, 61-81. 
5. Duncan, R. Drug-polymer conjugates: Potential for improved chemotherapy. Cancer Res. 1992, 46, 175-210.

6. Maeda, H.; Seymour, L.W.; Miyamoto, Y. Conjugates of anticancer agents and polymers-Advantages of macromolecular therapeutics in vivo. Bioconjugate Chem. 1992, 3, 351-362.

7. Seymour, L.W.; Miyamoto, Y.; Maeda, H.; Brereton, M.; Strohalm, J.; Ulbrich, K.; Duncan, R. Influence of molecular weight on passive tumor accumulation of a soluble macromolecular drug carrier. Eur. J. Cancer 1995, 31A, 766-770.

8. Matsumura, Y.; Maeda, H. A new concept for macromolecular therapeutics in cancer chemotherapy: Mechanism of tumoritropic accumulation of proteins and the antitumor agent smancs. Cancer Res. 1986, 46, 6387-6392.

9. Maeda, H.; Wu, J.; Sawa, T.; Matsumura, Y.; Hori, K. Tumor vascular permeability and the EPR effect in macromolecular therapeutics: A review. J. Control. Release 2000, 65, 271-284.

10. Seymour, L.W. Passive tumor targeting of soluble macromolecules and drug conjugates. Crit. Rev. Ther. Drug 1992, 9, 135-187.

11. Duncan, R.; Sat, Y.N. Tumour targeting by enhanced permeability and retention (EPR) effect. Ann. Oncol. 1998, 9, 39-39.

12. Wang, Z.; Itoh, Y.; Hosaka, Y.; Kobayashi, I.; Nakano, Y.; Maeda, I.; Umeda, F.; Yamakawa, J.; Nishimine, M.; Suenobu, T.; Fukuzumi, S.; Kawase, M.; Yagi, K. Mechanism of enhancement effect of dendrimer on transdermal drug permeation through polyhydroxyalkanoate matrix. J. Biosci. Bioeng. 2003, 96, 537-540.

13. Gillies, E.R.; Fréchet, J.M.J. Designing macromolecules for therapeutic applications: Polyester dendrimer-poly(ethylene oxide) "bow-tie" hybrids with tunable molecular weight and architecture. J. Am. Chem. Soc. 2002, 124, 14137-14146.

14. Kolhe, P.; Misra, E.; Kannan, R.M.; Kannan, S.; Lieh-Lai, M. Drug complexation, in vitro release and cellular entry of dendrimers and hyperbranched polymers. Int. J. Pharmaceut. 2003, 259, 143-160.

15. Baker, J.R. Why I believe nanoparticles are crucial as a carrier for targeted drug delivery. Wiley Interdiscip. Rev. Nanomed. Nanobiotechnol. 2013, 5, 423-429.

16. Gu, L.; Wu, Z.H.; Qi, X.L.; He, H.; Ma, X.L.; Chou, X.H.; Wen, X.G.; Zhang, M.; Jiao, F. Polyamidomine dendrimers: An excellent drug carrier for improving the solubility and bioavailability of puerarin. Pharm. Dev. Technol. 2013, 18, 1051-1057.

17. Zhou, Z.Y.; D'Emanuele, A.; Attwood, D. Solubility enhancement of paclitaxel using a linear-dendritic block copolymer. Int. J. Pharmaceut. 2013, 452, 173-179.

18. Gula, A.; Ren, L.; Zhou, Z.; Lu, D.D.; Wang, S.Q. Design and evaluation of biodegradable enteric microcapsules of amifostine for oral delivery. Int. J. Pharmaceut. 2013, 453, 441-447.

19. Ma, X.P.; Zhou, Z.X.; Jin, E.L.; Sun, Q.H.; Zhang, B.; Tang, J.B.; Shen, Y.Q. Facile synthesis of polyester dendrimers as drug delivery carriers. Macromolecules 2013, 46, 37-42.

20. Thomas, T.P.; Joice, M.; Sumit, M.; Silpe, J.E.; Kotlyar, A.; Bharathi, S.; Kukowska-Latallo, J.; Baker, J.R.; Choi, S.K. Design and in vitro validation of multivalent dendrimer methotrexates as a folate-targeting anticancer therapeutic. Curr. Pharm. Design 2013, 19, 6594-6605. 
21. Leng, Z.H.; Zhuang, Q.F.; Li, Y.C.; He, Z.; Chen, Z.; Huang, S.P.; Jia, H.Y.; Zhou, J.W.; Liu, Y.; Du, L.B. Polyamidoamine dendrimer conjugated chitosan nanoparticles for the delivery of methotrexate. Carbohyd. Polym. 2013, 98, 1173-1178.

22. Murugan, E.; Rani, D.P.G.; Srinivasan, K.; Muthumary, J. New surface hydroxylated and internally quaternised poly(propylene imine) dendrimers as efficient biocompatible drug carriers of norfloxacin. Expert Opin. Drug. Del. 2013, 10, 1319-1334.

23. Sadekar, S.; Thiagarajan, G.; Bartlett, K.; Hubbard, D.; Ray, A.; McGill, L.D.; Ghandehari, H. Poly(amido amine) dendrimers as absorption enhancers for oral delivery of camptothecin. Int. J. Pharmaceut. 2013, 456, 175-185.

24. Wang, L.; Xu, X.P.; Zhang, Y.; Zhang, Y.Q.; Zhu, Y.; Shi, J.Y.; Sun, Y.H.; Huang, Q. Encapsulation of curcumin within poly(amidoamine) dendrimers for delivery to cancer cells. J. Mater. Sci Mater. M. 2013, 24, 2137-2144.

25. Yellepeddi, V.K.; Vangara, K.K.; Palakurthi, S. Poly(amido)amine (PAMAM) dendrimer-cisplatin complexes for chemotherapy of cisplatin-resistant ovarian cancer cells. J. nanopart. Res. 2013, 15, doi:10.1007/s11051-013-1897-6.

26. Koc, F.E.; Senel, M. Solubility enhancement of non-steroidal anti-inflammatory drugs (NSAIDs) using polypolypropylene oxide core PAMAM dendrimers. Int. J. Pharmaceut. 2013, 451, 18-22.

27. Yabbarov, N.G.; Posypanova, G.A.; Vorontsov, E.A.; Obydenny, S.I.; Severin, E.S. A new system for targeted delivery of doxorubicin into tumor cells. J. Control. Release 2013, 168, 135-141.

28. Agrawal, U.; Mehra, N.K.; Gupta, U.; Jain, N.K. Hyperbranched dendritic nano-carriers for topical delivery of dithranol. J. Drug Target. 2013, 21, 497-506.

29. Daneshvar, N.; Abdullah, R.; Shamsabadi, F.T.; How, C.W.; Aizat, M.M.H.; Mehrbod, P. PAMAM dendrimer roles in gene delivery methods and stem cell research. Cell Biol. Int. 2013, 37, 415-419.

30. Richardson, R.K.; Dougherty, C.; DiMaggio, S.; Banaszak-Holl, M. Synthesis, isolation, and characterization of dendrimer conjugates as potential chemotherapy drug delivery systems. Abstr. pap. Am. Chem. S. 2013, 245, 856.

31. Cai, X.P.; Hu, J.J.; Xiao, J.R.; Cheng, Y.Y. Dendrimer and cancer: A patent review (2006-2013). Expert Opin. Ther. Pat. 2013, 23, 515-529.

32. Garea, S.A.; Ghebaur, E.V. Hybrid drug release systems based on dendrimers and montmorillonite. Mater. Plast. 2013, 50, 8-11.

33. Ly, T.U.; Tran, N.Q.; Thi, K.D.H.; Phan, K.N.; Truong, H.N.; Nguyen, C.K. Pegylated dendrimer and its effect in fluorouracil loading and release for enhancing antitumor activity. J. Biomed. Nanotechnol. 2013, 9, 213-220.

34. Wen, S.H.; Li, K.G.; Cai, H.D.; Chen, Q.; Shen, M.W.; Huang, Y.P.; Peng, C.; Hou, W.X.; Zhu, M.F.; Zhang, G.X.; et al. Multifunctional dendrimer-entrapped gold nanoparticles for dual mode CT/MR imaging applications. Biomaterials 2013, 34, 1570-1580.

35. Sharma, A.; Jain, N.; Sareen, R. Nanocarriers for diagnosis and targeting of breast cancer. Biomed. Res. Int. 2013, 2013, 960821:1- 960821:10.

36. Xu, L.Y.; Yeudall, W.A.; Yang, H. Tailored Polymer Architectures for Pharmaceutical and Biomedical Applications; Scholz, C., Kressler, J., Eds.; American Chemical Society: Washington, DC, USA, 2013; Volume 1135, pp. 197-213. 
37. Zhu, J.Y.; Shi, X.Y. Dendrimer-based nanodevices for targeted drug delivery applications. J. Mater. Chem. 2013, 1, 4199-4211.

38. Huang, C.H.; Nwe, K.; Al Zaki, A.; Brechbiel, M.W.; Tsourkas, A. Biodegradable polydisulfide dendrimer nanoclusters as MRI contrast agents. ACS Nano 2012, 6, 9416-9424.

39. Lim, J.; Turkbey, B.; Bernardo, M.; Bryant, L.H.; Garzoni, M.; Pavan, G.M.; Nakajima, T.; Choyke, P.L.; Simanek, E.E.; Kobayashi, H. Gadolinium MRI contrast agents based on triazine dendrimers: Relaxivity and in vivo pharmacokinetics. Bioconjugate Chem. 2012, 23, 2291-2299.

40. Carberry, T.P.; Tarallo, R.; Falanga, A.; Finamore, E.; Galdiero, M.; Weck, M.; Galdiero, S. Dendrimer functionalization with a membrane-interacting domain of herpes simplex virus type 1: Towards intracellular delivery. Chem. Eur. J. 2012, 18, 13678-13685.

41. Gardikis, K.; Micha-Screttas, M.; Demetzos, C.; Steele, B.R. Dendrimers and the development of new complex nanomaterials for biomedical applications. Curr. Med. Chem. 2012, 19, 4913-4928.

42. Klajnert, B.; Rozanek, M.; Bryszewska, M. Dendrimers in photodynamic therapy. Curr. Med. Chem. 2012, 19, 4903-4912.

43. Wate, P.S.; Banerjee, S.S.; Jalota-Badhwar, A.; Mascarenhas, R.R.; Zope, K.R.; Khandare, J.; Misra, R.D.K. Cellular imaging using biocompatible dendrimer-functionalized graphene oxide-based fluorescent probe anchored with magnetic nanoparticles. Nanotechnology 2012, 23, doi:10.1088/0957-4484/23/41/415101.

44. Andreani, T.; Macedo, A.S.; Ferreira, S.F.; Silva, A.M.; Rosmaninho, A.; Souto, E.B. Topical targeting therapies for sexually transmitted diseases. Curr. Nanosci. 2012, 8, 486-490.

45. Guo, R.; Shi, X.Y. Dendrimers in Cancer therapeutics and diagnosis. Curr. Drug Metab. 2012, 13, 1097-1109.

46. Thomas, T.P.; Huang, B.H.; Choi, S.K.; Silpe, J.E.; Kotlyar, A.; Desai, A.M.; Zong, H.; Gam, J.; Joice, M.; Baker, J.R. Polyvalent dendrimer-methotrexate as a folate receptor-targeted cancer therapeutic. Mol. Pharmaceut. 2012, 9, 2669-2676.

47. Holden, C.A.; Tyagi, P.; Thakur, A.; Kadam, R.; Jadhav, G.; Kompella, U.B.; Yang, H. Polyamidoamine dendrimer hydrogel for enhanced delivery of antiglaucoma drugs. Nanomed Nanotechnol. 2012, 8, 776-783.

48. Lim, J.; Simanek, E.E. Triazine dendrimers as drug delivery systems: From synthesis to therapy. Adv. Drug Delivery Rev. 2012, 64, 826-835.

49. Haque, S.; Md, S.; Alam, M.I.; Sahni, J.K.; Ali, J.; Baboota, S. Nanostructure-based drug delivery systems for brain targeting. Drug Dev. Ind. Pharm. 2012, 38, 387-411.

50. Svenson, S.; Tomalia, D.A. Commentary-dendrimers in biomedical applications-Reflections on the field. Adv. Drug Delivery Rev. 2005, 57, 2106-2129.

51. D'Emanuele, A.; Attwood, D. Dendrimer-drug interactions. Adv. Drug Delivery Rev. 2005, 57, 2147-2162.

52. Wolinsky, J.B.; Grinstaff, M.W. Therapeutic and diagnostic applications of dendrimers for cancer treatment. Adv. Drug Delivery Rev. 2008, 60, 1037-1055.

53. Cheng, Y.Y.; Xu, T.W. The effect of dendrimers on the pharmacodynamic and pharmacokinetic behaviors of non-covalently or covalently attached drugs. Eur. J. Med. Chem. 2008, 43, 2291-2297. 
54. Nanjwade, B.K.; Bechra, H.M.; Derkar, G.K.; Manvi, F.V.; Nanjwade, V.K. Dendrimers: Emerging polymers for drug-delivery systems. Eur. J. Pharmaceut. Sci. 2009, 38, 185-196.

55. Svenson, S. Dendrimers as versatile platform in drug delivery applications. Eur. J. Pharmaceut. Biopharmaceut. 2009, 71, 445-462.

56. Gillies, E.R.; Dy, E.; Fréchet, J.M.J.; Szoka, F.C. Biological evaluation of polyester dendrimer: Poly(ethylene oxide) "Bow-Tie" hybrids with tunable molecular weight and architecture. Mol. Pharmaceut. 2005, 2, 129-138.

57. Lee, C.C.; Gillies, E.R.; Fox, M.E.; Guillaudeu, S.J.; Fréchet, J.M.J.; Dy, E.E.; Szoka, F.C. A single dose of doxorubicin-functionalized bow-tie dendrimer cures mice bearing $\mathrm{C}-26$ colon carcinomas. Proc. Natl. Acad. Sci. USA 2006, 103, 16649-16654.

58. Carlmark, A.; Malmström, E.; Malkoch, M. Dendritic architectures based on bis-MPA: Functional polymeric scaffolds for application-driven research. Chem. Soc. Rev. 2013, 42, $5858-5879$.

59. Feliu, N.; Walter, M.V.; Montanez, M.I.; Kunzmann, A.; Hult, A.; Nyström, A.; Malkoch, M.; Fadeel, B. Stability and biocompatibility of a library of polyester dendrimers in comparison to polyamidoamine dendrimers. Biomaterials 2012, 33, 1970-1981.

60. Walter, M.V.; Malkoch, M. Simplifying the synthesis of dendrimers: Accelerated approaches. Chem. Soc. Rev. 2012, 41, 4593-4609.

61. Medina, S.H.; El-Sayed, M.E.H. Dendrimers as carriers for delivery of chemotherapeutic agents. Chem. Rev. 2009, 109, 3141-3157.

62. Ihre, H.R.; Padilla de Jesús, O.L.; Szoka, F.C.; Fréchet, J.M.J. Polyester dendritic systems for drug delivery applications: Design, synthesis, and characterization. Bioconjugate Chem. 2002, $13,443-452$.

63. Padilla de Jesús, O.L.; Ihre, H.R.; Gagne, L.; Fréchet, J.M.J.; Szoka, F.C. Polyester dendritic systems for drug delivery applications: In vitro and in vivo evaluation. Bioconjugate Chem. 2002, $13,453-461$.

64. Lazniewska, J.; Milowska, K.; Gabryelak, T. Dendrimers-Revolutionary drugs for infectious diseases. Wiley Interdiscip. Rev. Nanomed. Nanobiotechnol. 2012, 4, 469-491.

65. El Kazzouli, S.; El Brahmi, N.; Mignani, S.; Bousmina, M.; Zablocka, M.; Majoral, J.P. From metallodrugs to metallodendrimers for nanotherapy in oncology: A concise overview. Curr. Med. Chem. 2012, 19, 4995-5010.

66. Malik, N.; Evagorou, E.G.; Duncan, R. Dendrimer-platinate: A novel approach to cancer chemotherapy. Anticancer Drugs 1999, 10, 767-776.

67. Ahn, S.; Lee, I.H.; Lee, E.; Kim, H.; Kim, Y.C.; Jon, S. Oral delivery of an anti-diabetic peptide drug via conjugation and complexation with low molecular weight chitosan. J. Control. Release 2013, 170, 226-232.

68. Sangwai, M.; Vavia, P. Amorphous ternary cyclodextrin nanocomposites of telmisartan for oral drug delivery: Improved solubility and reduced pharmacokinetic variability. Int. J. Pharmaceut. 2013, 453, 423-432.

69. Higuchi, W.I.; Ho, N.F.H.; Merkle, H.P. Design of oral-drug delivery systems—Past, present and future. Drug Dev. Ind. Pharm. 1983, 9, 1227-1239. 
70. Mitra, S.B. Oral sustained-release drug delivery system using polymer film composites. Abstr. Pap. Am. Chem. S. 1983, 185, 119.

71. Kulhari, H.; Kulhari, D.P.; Prajapati, S.K.; Chauhan, A.S. Pharmacokinetic and pharmacodynamic studies of poly(amidoamine) dendrimer based simvastatin oral formulations for the treatment of hypercholesterolemia. Mol. Pharmaceut. 2013, 10, 2528-2533.

72. Gajbhiye, V.; Kumar, P.V.; Sharma, A.; Agarwal, A.; Asthana, A.; Jain, N.K. Dendrimeric nanoarchitectures mediated transdermal and oral delivery of bioactives. Indian J. Pharm. Sci. 2008, 70, 431-439.

73. Ke, W.L.; Zhao, Y.S.; Huang, R.Q.; Jiang, C.; Pei, Y.Y. Enhanced oral bioavailability of doxorubicin in a dendrimer drug delivery system. J. Pharm. Sci. 2008, 97, 2208-2216.

74. Kolhatkar, R.B.; Swaan, P.; Ghandehari, H. Potential oral delivery of 7-Ethyl-10-hydroxycamptothecin (SN-38) using poly(amidoamine) dendrimers. Pharm. Res. 2008, 25, 1723-1729.

75. Najlah, M.; Freeman, S.; Attwood, D.; D'Emanuele, A. Design and assessment of drug-dendrimer conjugates for oral drug delivery. J. Pharm. Pharmacol. 2004, 56, S67-S67.

76. Kalhapure, R.S.; Akamanchi, K.G. Oleodendrimers: A novel class of multicephalous heterolipids as chemical penetration enhancers for transdermal drug delivery. Int. J. Pharmaceut. 2013, 454, $158-166$.

77. Filipowicz, A.; Wolowiec, S. Solubility and in vitro transdermal diffusion of riboflavin assisted by PAMAM dendrimers. Int. J. Pharmaceut. 2011, 408, 152-156.

78. Borowska, K.; Laskowska, B.; Magon, A.; Mysliwiec, B.; Pyda, M.; Wolowiec, S. PAMAM dendrimers as solubilizers and hosts for 8-methoxypsoralene enabling transdermal diffusion of the guest. Int. J. Pharmaceut. 2010, 398, 185-189.

79. Venuganti, V.V.K.; Perumal, O.P. Poly(amidoamine) dendrimers as skin penetration enhancers: Influence of charge, generation, and concentration. J. Pharm. Sci. 2009, 98, 2345-2356.

80. Cheng, Y.Y.; Man, N.; Xu, T.W.; Fu, R.Q.; Wang, X.Y.; Wang, X.M.; Wen, L.P. Transdermal delivery of nonsteroidal anti-inflammatory drugs mediated by polyamidoamine (PAMAM) dendrimers. J. Pharm. Sci. 2007, 96, 595-602.

81. Chauhan, A.S.; Sridevi, S.; Chalasani, K.B.; Jain, A.K.; Jain, S.K.; Jain, N.K.; Diwan, P.V. Dendrimer-mediated transdermal delivery: Enhanced bioavailability of indomethacin. J. Control. Release 2003, 90, 335-343.

82. Gaudana, R.; Ananthula, H.; Parenky, A.; Mitra, A. Ocular drug delivery. AAPS J. 2010, 12, 348-360.

83. Yang, H.; Kao, W.J. Dendrimers for pharmaceutical and biomedical applications. J. Biomat. Sci Polym. E. 2006, 17, 3-19.

84. Kambhampati, S.P.; Kannan, R.M. Dendrimer nanoparticles for ocular drug delivery. J. Ocul. Pharmacol. Ther. 2013, 29, 151-165.

85. Fernandez, L.; Calderon, M.; Martinelli, M.; Strumia, M.; Cerecetto, H.; Gonzalez, M.; Silber, J.J.; Santo, M. Evaluation of a new dendrimeric structure as prospective drugs carrier for intravenous administration of antichagasic active compounds. J. Phys. Org. Chem. 2008, 21, 1079-1085. 
86. Kaminskas, L.M.; Kota, J.; McLeod, V.M.; Kelly, B.D.; Karellas, P.; Porter, C.J.H. PEGylation of polylysine dendrimers improves absorption and lymphatic targeting following SC administration in rats. J. Control. Release 2009, 140, 108-116.

87. Merkel, O.M.; Mintzer, M.A.; Librizzi, D.; Samsonova, O.; Dicke, T.; Sproat, B.; Garn, H.; Barth, P.J.; Simanek, E.E.; Kissel, T. Triazine dendrimers as nonviral vectors for in vitro and in vivo RNAi: The effects of peripheral groups and core structure on biological activity. Mol. Pharmaceut. 2010, 7, 969-983.

88. Navath, R.S.; Kurtoglu, Y.E.; Wang, B.; Kannan, S.; Romero, R.; Kannan, R.M. Dendrimer-drug conjugates for tailored intracellular drug release based on glutathione levels. Bioconjugate Chem. 2008, 19, 2446-2455.

89. Ward, B.B.; Huang, B.H.; Desai, A.; Cheng, X.M.; Vartanian, M.; Zong, H.; Shi, X.Y.; Thomas, T.P.; Kotlyar, A.E.; van der Spek, A.; et al. Sustained analgesia achieved through esterase-activated morphine prodrugs complexed with PAMAM dendrimer. Pharm. Res. 2013, 30, 247-256.

90. Duncan, R. Polymer conjugates as anticancer nanomedicines. Nat. Rev. Cancer 2006, 6, 688-701.

91. Harris, J.M.; Chess, R.B. Effect of pegylation on pharmaceuticals. Nat. Rev. Drug Discov. 2003, 2, 214-221.

92. Bae, Y.; Fukushima, S.; Harada, A.; Kataoka, K. Design of environment-sensitive supramolecular assemblies for intracellular drug delivery: Polymeric micelles that are responsive to intracellular pH change. Angew. Chem. Int. Ed. 2003, 42, 4640-4643.

93. Kataoka, K.; Harada, A.; Nagasaki, Y. Block copolymer micelles for drug delivery: Design, characterization and biological significance. Adv. Drug Delivery Rev. 2001, 47, 113-131.

94. Kataoka, K.; Harashima, H. Gene delivery systems: Viral vs. non-viral vectors. Adv. Drug Delivery Rev. 2001, 52, 151-151.

95. Vasey, P.A.; Kaye, S.B.; Morrison, R.; Twelves, C.; Wilson, P.; Duncan, R.; Thomson, A.H.; Murray, L.S.; Hilditch, T.E.; Murray, T.; et al. Phase I clinical and pharmacokinetic study of PK1 N-(2-hydroxypropyl)methacrylamide copolymer doxorubicin: First member of a new class of chemotherapeutic agents-Drug-polymer conjugates. Clinic. Cancer Res. 1999, 5, 83-94.

96. Gillies, E.R.; Fréchet, J.M.J. Dendrimers and dendritic polymers in drug delivery. Drug Discov. Today 2005, 10, 35-43.

97. Gillies, E.R.; Goodwin, A.P.; Fréchet, J.M.J. Acetals as pH-sensitive linkages for drug delivery. Bioconjugate Chem. 2004, 15, 1254-1263.

98. Van der Poll, D.G.; Kieler-Ferguson, H.M.; Floyd, W.C.; Guillaudeu, S.J.; Jerger, K.; Szoka, F.C.; Fréchet, J.M. Design, synthesis, and biological evaluation of a robust, biodegradable dendrimer. Bioconjugate Chem. 2010, 21, 764-773.

99. Nakanishi, T.; Fukushima, S.; Okamoto, K.; Suzuki, M.; Matsumura, Y.; Yokoyama, M.; Okano, T.; Sakurai, Y.; Kataoka, K. Development of the polymer micelle carrier system for doxorubicin. J. Control. Release 2001, 74, 295-302.

100. Haag, R. Supramolecular drug-delivery systems based on polymeric core-shell architectures. Angew. Chem. Int. Ed. 2004, 43, 278-282. 
101. Morgan, M.T.; Nakanishi, Y.; Kroll, D.J.; Griset, A.P.; Carnahan, M.A.; Wathier, M.; Oberlies, N.H.; Manikumar, G.; Wani, M.C.; Grinstaff, M.W. Dendrimer-encapsulated camptothecins: Increased solubility, cellular uptake, and cellular retention affords enhanced anticancer activity in vitro. Cancer Res. 2006, 66, 11913-11921.

102. Dhanikula, R.S.; Hildgen, P. Synthesis and evaluation of novel dendrimers with a hydrophilic interior as nanocarriers for drug delivery. Bioconjugate Chem. 2006, 17, $29-41$.

103. Nazemi, A.; Haeryfar, S.M.M.; Gillies, E.R. Multifunctional dendritic sialopolymersomes as potential antiviral agents: Their lectin binding and drug release properties. Langmuir 2013, 29, 6420-6428.

104. Kim, S.H.; Tan, J.P.K.; Nederberg, F.; Fukushima, K.; Yang, Y.Y.; Waymouth, R.M.; Hedrick, J.L. Mixed micelle formation through stereocomplexation between enantiomeric poly(lactide) block copolymers. Macromolecules 2009, 42, 25-29.

105. Skey, J.; Hansell, C.F.; O’Reilly, R.K. Stabilization of amino acid derived diblock copolymer micelles through favorable D:L side chain interactions. Macromolecules 2010, 43, 1309-1318.

106. Moughton, A.O.; O'Reilly, R.K. Noncovalently connected micelles, nanoparticles, and metal-functionalized nanocages using supramolecular self-assembly. J. Am. Chem. Soc. 2008, 130, 8714-8725.

107. Fukushima, K.; Pratt, R.C.; Nederberg, F.; Tan, J.P.K.; Yang, Y.Y.; Waymouth, R.M.; Hedrick, J.L. Organocatalytic approach to amphiphilic comb-block copolymers capable of stereocomplexation and self-assembly. Biomacromolecules 2008, 9, 3051-3056.

108. Nederberg, F.; Appel, E.; Tan, J.P.K.; Kim, S.H.; Fukushima, K.; Sly, J.; Miller, R.D.; Waymouth, R.M.; Yang, Y.Y.; Hedrick, J.L. Simple approach to stabilized micelles employing miktoarm terpolymers and stereocomplexes with application in paclitaxel delivery. Biomacromolecules 2009, 10, 1460-1468.

109. Weaver, J.V.M.; Tang, Y.Q.; Liu, S.Y.; Iddon, P.D.; Grigg, R.; Billingham, N.C.; Armes, S.P.; Hunter, R.; Rannard, S.P. Preparation of shell cross-linked micelles by polyelectrolyte complexation. Angew. Chem. Int. Ed. 2004, 43, 1389-1392.

110. Giacomelli, C.; Schmidt, V.; Borsali, R. Specific interactions improve the loading capacity of block copolymer micelles in aqueous media. Langmuir 2007, 23, 6947-6955.

111. Chiang, Y.T.; Cheng, Y.T.; Lu, C.Y.; Yen, Y.W.; Yu, L.Y.; Yu, K.S.; Lyu, S.Y.; Yang, C.Y.; Lo, C.L. Polymer-liposome complexes with a functional hydrogen-bond cross-linker for preventing protein adsorption and improving tumor accumulation. Chem. Mater. 2013, 25, 4364-4372.

112. Hutin, M.; Burakowska-Meise, E.; Appel, W.P.J.; Dankers, P.Y.W.; Meijer, E.W. From molecular structure to macromolecular organization: Keys to design supramolecular biomaterials. Macromolecules 2013, 46, 8528-8537.

113. Zhu, Z.C.; Gao, N.; Wang, H.J.; Sukhishvili, S.A. Temperature-triggered on-demand drug release enabled by hydrogen-bonded multilayers of block copolymer micelles. J. Control. Release 2013, 171, 73-80.

114. Tadi, K.K.; Motghare, R.V. Rational synthesis of pindolol imprinted polymer by non-covalent protocol based on computational approach. J. Mol. Model. 2013, 19, 3385-3396.

115. Sanyakamdhorn, S.; Agudelo, D.; Tajmir-Riahi, H.A. Encapsulation of antitumor drug doxorubicin and its analogue by chitosan nanoparticles. Biomacromolecules 2013, 14, 557-563. 
116. Kim, S.H.; Tan, J.P.K.; Nederberg, F.; Fukushima, K.; Colson, J.; Yang, C.A.; Nelson, A.; Yang, Y.Y.; Hedrick, J.L. Hydrogen bonding-enhanced micelle assemblies for drug delivery. Biomaterials 2010, 31, 8063-8071.

117. Zhou, J.; Soontornworajit, B.; Martin, J.; Sullenger, B.A.; Gilboa, E.; Wang, Y. A hybrid DNA aptamer-dendrimer nanomaterial for targeted cell labeling. Macromol. Biosci. 2009, 9, 831-835.

118. Battig, M.R.; Soontornworajit, B.; Wang, Y. Programmable release of multiple protein drugs from aptamer-functionalized hydrogels via nucleic acid hybridization. J. Am. Chem. Soc. 2012, $134,12410-12413$.

119. Zhang, Z.Y.; Chen, N.C.; Li, S.H.; Battig, M.R.; Wang, Y. Programmable hydrogels for controlled cell catch and release using hybridized aptamers and complementary sequences. J. Am. Chem. Soc. 2012, 134, 15716-15719.

120. Soontornworajit, B.; Zhou, J.; Zhang, Z.Y.; Wang, Y. Aptamer-functionalized in situ injectable hydrogel for controlled protein release. Biomacromolecules 2010, 11, 2724-2730.

121. Zhou, J.; Soontornworajit, B.; Wang, Y. A temperature-responsive antibody-like nanostructure. Biomacromolecules 2010, 11, 2087-2093.

122. Morgan, M.T.; Carnahan, M.A.; Immoos, C.E.; Ribeiro, A.A.; Finkelstein, S.; Lee, S.J.; Grinstaff, M.W. Dendritic molecular capsules for hydrophobic compounds. J. Am. Chem. Soc. 2003, 125, 15485-15489.

123. Antoni, P.; Hed, Y.; Nordberg, A.; Nyström, D.; von Holst, H.; Hult, A.; Malkoch, M. Bifunctional dendrimers: From robust synthesis and accelerated one-pot postfunctionalization strategy to potential applications. Angew. Chem. Int. Ed. 2009, 48, 2126-2130.

124. Jain, K.; Kesharwani, P.; Gupta, U.; Jain, N.K. Dendrimer toxicity: Let's meet the challenge. Int. J. Pharmaceut. 2010, 394, 122-142.

125. Bernkop-Schnurch, A.; Scholler, S.; Biebel, R.G. Development of controlled drug release systems based on thiolated polymers. J. Control. Release 2000, 66, 39-48.

126. Hawker, C.J.; Fréchet, J.M.J. Unusual macromolecular architectures-The convergent growth approach to dendritic polyesters and novel block copolymers. J. Am. Chem. Soc. 1992, 114, 8405-8413.

127. Haddleton, D.M.; Sahota, H.S.; Taylor, P.C.; Yeates, S.G. Synthesis of polyester dendrimers. J. Chem. Soc. Perkin Trans. 1 1996, 649-656.

128. Antoni, P.; Nyström, D.; Hawker, C.J.; Hult, A.; Malkoch, M. A chemoselective approach for the accelerated synthesis of well-defined dendritic architectures. Chem. Commun. 2007, 2249-2251.

129. Ihre, H.; Hult, A.; Söderlind, E. Synthesis, characterization, and H-1 NMR self-diffusion studies of dendritic aliphatic polyesters based on 2,2-bis(hydroxymethyl)propionic acid and 1,1,1-tris(hydroxyphenyl)ethane. J. Am. Chem. Soc. 1996, 118, 6388-6395.

130. Ihre, H.; Padilla de Jesús, O.L.; Fréchet, J.M.J. Fast and convenient divergent synthesis of aliphatic ester dendrimers by anhydride coupling. J. Am. Chem. Soc. 2001, 123, 5908-5917.

131. Parrott, M.C.; Benhabbour, S.R.; Saab, C.; Lemon, J.A.; Parker, S.; Valliant, J.F.; Adronov, A. Synthesis, radiolabeling, and bio-imaging of high-generation polyester dendrimers. J. Am. Chem. Soc. 2009, 131, 2906-2916. 
132. Bouillon, C.; Tintaru, A.; Monnier, V.; Charles, L.; Quelever, G.; Peng, L. Synthesis of poly(amino)ester dendrimers via active cyanomethyl ester intermediates. J. Org. Chem. 2010, 75, 8685-8688.

133. Twibanire, J.K.; Al-Mughaid, H.; Grindley, T.B. Synthesis of new cores and their use in the preparation of polyester dendrimers. Tetrahedron 2010, 66, 9602-9609.

134. Keefe, G.E.; Twibanire, J.K.; Grindley, T.B.; Shaver, M.P. Poly(lactic acid) polymer stars built from early generation dendritic polyols. Can. J. Chem. 2013, 91, 392-397.

135. Twibanire, J.K.; Grindley, T.B. Polyester dendrimers. Polymers 2012, 4, 794-879.

136. Knorr, R.; Trzeciak, A.; Bannwarth, W.; Gillessen, D. New coupling reagents in peptide chemistry. Tetrahedron Lett. 1989, 30, 1927-1930.

137. Carpino, L.A. 1-Hydroxy-7-azabenzotriazole-An efficient peptide coupling additive. J. Am. Chem. Soc. 1993, 115, 4397-4398.

138. El-Faham, A.; Subirós Funosas, R.; Prohens, R.; Albericio, F. COMU: A safer and more effective replacement for benzotriazole-based uronium coupling reagents. Chem. Eur. J. 2009, 15, 9404-9416.

139. Twibanire, J.K.; Grindley, T.B. Efficient and controllably selective preparation of esters using uronium-based coupling agents. Org. Lett. 2011, 13, 2988-2991.

140. Twibanire, J.K.; Omran, R.P.; Grindley, T.B. Facile synthesis of a library of lyme disease glycolipid antigens. Org. Lett. 2012, 14, 3909-3911.

141. Paul, N.K.; Twibanire, J.K.; Grindley, T.B. Direct synthesis of maradolipids and other trehalose 6-monoesters and 6,6'-diesters. J. Org. Chem. 2013, 78, 363-369.

142. Hawker, C.J.; Fréchet, J.M.J. Preparation of polymers with controlled molecular architecture-A new convergent approach to dendritic macromolecules. J. Am. Chem. Soc. 1990, 112, 7638-7647.

143. Hawker, C.J.; Fréchet, J.M.J. A new convergent approach to monodisperse dendritic macromolecules. J. Chem. Soc. Chem. Commun. 1990, 1990, 1010-1013.

144. Hawker, C.J.; Lee, R.; Fréchet, J.M.J. One-step synthesis of hyperbranched dendritic polyesters. J. Am. Chem. Soc. 1991, 113, 4583-4588.

145. Hawker, C.J.; Fréchet, J.M.J. Monodispersed dendritic polyesters with removable chain ends-A versatile approach to globular macromolecules with chemically reversible polarities. J. Chem. Soc. Perkin Trans. 1 1992, 2459-2469.

146. Guillaudeu, S.J.; Fox, M.E.; Haidar, Y.M.; Dy, E.E.; Szoka, F.C.; Fréchet, J.M.J. PEGylated dendrimers with core functionality for biological applications. Bioconjugate Chem. 2008, 19, 461-469.

147. Gillies, E.R.; Fréchet, J.M.J. Synthesis and self-assembly of supramolecular dendritic "Bow-Ties": Effect of peripheral functionality on association constants. J. Org. Chem. 2004, 69, 46-53.

148. Krishna, R.; Mayer, L.D. Liposomal doxorubicin circumvents PSC 833-free drug interactions, resulting in effective therapy of multidrug-resistant solid tumors. Cancer Res. 1997, 57, 5246-5253.

149. Kaneko, T.; Willner, D.; Monkovic, I.; Knipe, J.O.; Braslawsky, G.R.; Greenfield, R.S.; Vyas, D.M. New hydrazone derivatives of Adriamycin and their immunoconjugates: A correlation between acid stability and cytotoxicity. Bioconjugate Chem. 1991, 2, 133-141. 
150. Lee, C.C.; Cramer, A.T.; Szoka, F.C.; Frechet, J.M.J. An intramolecular cyclization reaction is responsible for the in vivo inefficacy and apparent $\mathrm{pH}$ insensitive hydrolysis kinetics of hydrazone carboxylate derivatives of doxorubicin. Bioconjugate Chem. 2006, 17, 1364-1368.

151. Duncan, R. The dawning era of polymer therapeutics. Nat. Rev. Drug Discov. 2003, 2, 347-360.

152. Seymour, L.W.; Ulbrich, K.; Steyger, P.S.; Brereton, M.; Subr, V.; Strohalm, J.; Duncan, R. Tumor tropism and anticancer efficacy of polymer-based doxorubicin prodrugs in the treatment of subcutaneous murine b16f10 melanoma. Brit. J. Cancer 1994, 70, 636-641.

153. Huang, S.K.; Mayhew, E.; Gilani, S.; Lasic, D.D.; Martin, F.J.; Papahadjopoulos, D. Pharmacokinetics and therapeutics of sterically stabilized liposomes in mice bearing C-26 colon-carcinoma. Cancer Res. 1992, 52, 6774-6781.

154. Mayhew, E.G.; Goldrosen, M.H.; Vaage, J.; Rustum, Y.M. Effects of liposome-entrapped doxorubicin on liver metastases of mouse colon carcinoma-26 and carcinoma-38. J. Natl. Cancer Inst. 1987, 78, 707-713.

155. Namazi, H.; Bahrami, S.; Entezami, A.A. Synthesis and controlled release of biocompatible prodrugs of beta-cyclodextrin linked with PEG containing ibuprofen or indomethacin. Iran. Polym. J. 2005, 14, 921-927.

156. Namazi, H.; Adeli, M. Novel linear-globular thermoreversible hydrogel ABA type copolymers from dendritic citric acid as the A blocks and poly(ethyleneglycol) as the B block. Eur. Polym. J. 2003, 39, 1491-1500.

157. Namazi, H.; Adell, M. Dendrimers of citric acid and poly (ethylene glycol) as the new drug-delivery agents. Biomaterials 2005, 26, 1175-1183.

158. Hawthorne, M.F. The role of chemistry in the development of boron neutron-capture therapy of cancer. Angew. Chem. Int. Ed. Engl. 1993, 32, 950-984.

159. Soloway, A.H.; Tjarks, W.; Barnum, B.A.; Rong, F.G.; Barth, R.F.; Codogni, I.M.; Wilson, J.G. The chemistry of neutron capture therapy. Chem. Rev. 1998, 98, 1515-1562.

160. Kawabata, S.; Hiramatsu, R.; Kuroiwa, T.; Ono, K.; Miyatake, S.-I. Boron neutron capture therapy for recurrent high-grade meningiomas Clinical article. J. Neurosurg. 2013, 119, 837-844.

161. Sun, T.; Zhang, Z.; Li, B.; Chen, G.; Xie, X.; Wei, Y.; Wu, J.; Zhou, Y.; Du, Z. Boron neutron capture therapy induces cell cycle arrest and cell apoptosis of glioma stem/progenitor cells in vitro. Radiat. Oncol. 2013, 8, doi:10.1186/1748-717X-8-195.

162. Hawthorne, M.F.; Lee, M.W. A critical assessment of boron target compounds for boron neutron capture therapy. J. Neuro Oncol. 2003, 62, 33-45.

163. Parrott, M.C.; Marchington, E.B.; Valliant, J.F.; Adronov, A. Synthesis and properties of carborane-functionalized aliphatic polyester dendrimers. J. Am. Chem. Soc. 2005, 127, 12081-12089.

164. Newkome, G.R.; Moorefield, C.N.; Keith, J.M.; Baker, G.R.; Escamilla, G.H. Chemistry within a unimolecular micelle precursor: Boron superclusters by site-specific and depth-specific transformations of dendrimers. 37. Chemistry of micelles. Angew. Chem. Int. Ed. Engl. 1994, 33, 666-668.

165. Cragg, G.M.; Newman, D.J.; Snader, K.M. Natural products in drug discovery and development. J. Nat. Prod. 1997, 60, 52-60. 
166. Cragg, G.M.; Newman, D.J.; Weiss, R.B. Coral reefs, forests, and thermal vents: The worldwide exploration of nature for novel antitumor agents. Semin. Oncol. 1997, 24, 156-163.

167. Oberlies, N.H.; Kroll, D.J. Camptothecin and taxol: Historic achievements in natural products research. J. Nat. Prod. 2004, 67, 129-135.

168. Garcia-Carbonero, R.; Supko, J.G. Current perspectives on the clinical experience, pharmacology, and continued development of the camptothecins. Clinic. Cancer Res. 2002, 8, 641-661.

169. Thomas, C.J.; Rahier, N.J.; Hecht, S.M. Camptothecin: Current perspectives. Bioorg. Med. Chem. 2004, 12, 1585-1604.

170. Sriram, D.; Yogeeswari, P.; Thirumurugan, R.; Bal, T.R. Camptothecin and its analogues: A review on their chemotherapeutic potential. Nat. Prod. Res. 2005, 19, 393-412.

171. Hecht, J.R. Gastrointestinal toxicity of irinotecan. Oncology NY 1998, 12, 72-78.

172. Armstrong, D.K. Topotecan dosing guidelines in ovarian cancer: Reduction and management of hematologic toxicity. Oncologist 2004, 9, 33-42.

173. Feng, X.S.; Pinaud, J.; Chaikof, E.L.; Taton, D.; Gnanou, Y. Sequential functionalization of janus-type dendrimer-like poly(ethylene oxide)s with camptothecin and folic acid. J. Polym. Sci. Part A Polym. Sci. 2011, 49, 2839-2849.

174. Fox, M.E.; Guillaudeu, S.; Fréchet, J.M.J.; Jerger, K.; Macaraeg, N.; Szoka, F.C. Synthesis and in vivo antitumor efficacy of pegylated poly(l-lysine) dendrimer-camptothecin conjugates. Mol. Pharmaceut. 2009, 6, 1562-1572.

175. Thiagarajan, G.; Ray, A.; Malugin, A.; Ghandehari, H. PAMAM-camptothecin conjugate inhibits proliferation and induces nuclear fragmentation in colorectal carcinoma cells. Pharm. Res. 2010, 27, 2307-2316.

176. Bolten, B.M.; DeGregorio, T. Trends in development cycles. Nat. Rev. Drug Discov. 2002, 1, 335-336.

177. Langer, R. Drug delivery and targeting. Nature 1998, 392, 5-10.

178. Dhanikula, R.S.; Hildgen, P. Influence of molecular architecture of polyether-co-polyester dendrimers on the encapsulation and release of methotrexate. Biomaterials 2007, 28, 3140-3152.

179. Lee, C.C.; Yoshida, M.; Fréchet, J.M.J.; Dy, E.E.; Szoka, F.C. In vitro and in vivo evaluation of hydrophilic dendronized linear polymers. Bioconjugate Chem. 2005, 16, 535-541.

180. Lee, C.C.; Grayson, S.M.; Fréchet, J.M.J. Synthesis of narrow-polydispersity degradable dendronized aliphatic polyesters. J. Polym. Sci. Part A Polym. Sci. 2004, 42, 3563-3578.

181. Goldspiel, B.R. Clinical overview of the taxanes. Pharmacotherapy 1997, 17, S110-S125.

182. Wang, T.H.; Wang, H.S.; Soong, Y.K. Paclitaxel-induced cell death-Where the cell cycle and apoptosis come together. Cancer 2000, 88, 2619-2628.

183. Szebeni, J.; Muggia, F.M.; Alving, C.R. Complement activation by cremophor EL as a possible contributor to hypersensitivity to paclitaxel: An in vitro study. J. Natl. Cancer Inst. 1998, 90, 300-306.

184. Hennenfent, K.L.; Govindan, R. Novel formulations of taxanes: A review. Old wine in a new bottle? Ann. Oncol. 2006, 17, 735-749.

185. Wu, J.; Liu, Q.; Lee, R.J. A folate receptor-targeted liposomal formulation for paclitaxel. Int. J. Pharmaceut. 2006, 316, 148-153. 
186. Ooya, T.; Lee, J.; Park, K. Hydrotropic dendrimers of generations 4 and 5: Synthesis, characterization, and hydrotropic solubilization of paclitaxel. Bioconjugate Chem. 2004, 15, 1221-1229.

187. Le Garrec, D.; Gori, S.; Luo, L.; Lessard, D.; Smith, D.C.; Yessine, M.A.; Ranger, M.; Leroux, J.C. Poly(N-vinylpyrrolidone)-block-poly(D,L-lactide) as a new polymeric solubilizer for hydrophobic anticancer drugs: In vitro and in vivo evaluation. J. Control. Release 2004, 99, 83-101.

188. Lee, S.C.; Huh, K.M.; Lee, J.; Cho, Y.W.; Galinsky, R.E.; Park, K. Hydrotropic polymeric micelles for enhanced paclitaxel solubility: In vitro and in vivo characterization. Biomacromolecules 2007, 8, 202-208.

189. Khandare, J.J.; Jayant, S.; Singh, A.; Chandna, P.; Wang, Y.; Vorsa, N.; Minko, T. Dendrimer versus linear conjugate: Influence of polymeric architecture on the delivery and anticancer effect of paclitaxel. Bioconjugate Chem. 2006, 17, 1464-1472.

190. Majoros, I.J.; Myc, A.; Thomas, T.; Mehta, C.B.; Baker, J.R. PAMAM dendrimer-based multifunctional conjugate for cancer therapy: Synthesis, characterization, and functionality. Biomacromolecules 2006, 7, 572-579.

191. Zhang, Z.P.; Feng, S.S. The drug encapsulation efficiency, in vitro drug release, cellular uptake and cytotoxicity of paclitaxel-loaded poly(lactide)-tocopheryl polyethylene glycol succinate nanoparticles. Biomaterials 2006, 27, 4025-4033.

192. Ceruti, M.; Crosasso, P.; Brusa, P.; Arpicco, S.; Dosio, F.; Cattel, L. Preparation, characterization, cytotoxicity and pharmacokinetics of liposomes containing water-soluble prodrugs of paclitaxel. J. Control. Release 2000, 63, 141-153.

193. Crosasso, P.; Ceruti, M.; Brusa, P.; Arpicco, S.; Dosio, F.; Cattel, L. Preparation, characterization and properties of sterically stabilized paclitaxel-containing liposomes. J. Control. Release $\mathbf{2 0 0 0 ,}$ 63, 19-30.

194. Kontoyianni, C.; Sideratou, Z.; Theodossiou, T.; Tziveleka, L.A.; Tsiourvas, D.; Paleos, C.M. A novel micellar PEGylated hyperbranched polyester as a prospective drug delivery system for paclitaxel. Macromol. Biosci. 2008, 8, 871-881.

195. Malmström, E.; Johansson, M.; Hult, A. Hyperbranched aliphatic polyesters. Macromolecules 1995, 28, 1698-1703.

196. Gupta, U.; Agashe, H.B.; Asthana, A.; Jain, N.K. Dendrimers: Novel polymeric nanoarchitectures for solubility enhancement. Biomacromolecules 2006, 7, 649-658.

197. Reul, R.; Renette, T.; Bege, N.; Kissel, T. Nanoparticles for paclitaxel delivery: A comparative study of different types of dendritic polyesters and their degradation behavior. Int. J. Pharmaceut. 2011, 407, 190-196.

198. Chen, S.; Zhang, X.Z.; Cheng, S.X.; Zhuo, R.X.; Gu, Z.W. Functionalized amphiphilic hyperbranched polymers for targeted drug delivery. Biomacromolecules 2008, 9, 2578-2585.

199. Wang, J.; Xu, T. Facile construction of multivalent targeted drug delivery system from Boltorn- ${ }^{\circledR}$ series hyperbranched aliphatic polyester and folic acid. Polym. Adv. Technol. 2011, $22,763-767$. 
200. Zeng, X.H.; Zhang, Y.N.; Wu, Z.H.; Lundberg, P.; Malkoch, M.; Nyström, A.M. Hyperbranched copolymer micelles as delivery vehicles of doxorubicin in breast cancer cells. J. Polym. Sci. Part A Polym. Sci. 2012, 50, 280-288.

201. Fox, M.E.; Szoka, F.C.; Fréchet, J.M.J. Soluble polymer carriers for the treatment of cancer: The importance of molecular architecture. Acc. Chem. Res. 2009, 42, 1141-1151.

202. Akiyoshi, K.; Deguchi, S.; Moriguchi, N.; Yamaguchi, S.; Sunamoto, J. Self-aggregates of hydrophobized polysaccharides in water-Formation and characteristics of nanoparticles. Macromolecules 1993, 26, 3062-3068.

203. Kwon, G.S.; Kataoka, K. Block-copolymer micelles as long-circulating drug vehicles. Adv. Drug Delivery Rev. 1995, 16, 295-309.

204. Torchilin, V.P. Structure and design of polymeric surfactant-based drug delivery systems. J. Control. Release 2001, 73, 137-172.

205. Jones, M.C.; Leroux, J.C. Polymeric micelles-A new generation of colloidal drug carriers. Eur. J. Pharmaceut. Biopharmaceut. 1999, 48, 101-111.

206. Lawrence, M.J. Surfactant systems-Their use in drug-delivery. Chem. Soc. Rev. 1994, 23, 417-424.

207. Cao, W.Q.; Zhou, J.; Mann, A.; Wang, Y.; Zhu, L. Folate-functionalized unimolecular micelles based on a degradable amphiphilic dendrimer-like star polymer for cancer cell-targeted drug delivery. Biomacromolecules 2011, 12, 2697-2707.

208. Cao, W.Q.; Zhu, L. Synthesis and unimolecular micelles of amphiphilic dendrimer-like star polymer with various functional surface groups. Macromolecules 2011, 44, 1500-1512.

209. Cao, W.Q.; Zhou, J.; Wang, Y.; Zhu, L. Synthesis and in vitro cancer cell targeting of folate-functionalized biodegradable amphiphilic dendrimer-like star polymers. Biomacromolecules 2010, 11, 3680-3687.

210. Pan, X.Q.; Wang, H.Q.; Lee, R.J. Antitumor activity of folate receptor-targeted liposomal doxorubicin in a KB oral carcinoma murine xenograft model. Pharm. Res. 2003, 20, 417-422.

211. Lu, Y.J.; Low, P.S. Folate-mediated delivery of macromolecular anticancer therapeutic agents. Adv. Drug Delivery Rev. 2002, 54, 675-693.

212. Wang, S.; Low, P.S. Folate-mediated targeting of antineoplastic drags, imaging agents, and nucleic acids to cancer cells. J. Control.Release 1998, 53, 39-48.

213. Brinkhuis, R.P.; Rutjes, F.; van Hest, J.C.M. Polymeric vesicles in biomedical applications. Polym. Chem. 2011, 2, 1449-1462.

214. Pourtau, L.; Oliveira, H.; Thevenot, J.; Wan, Y.L.; Brisson, A.R.; Sandre, O.; Miraux, S.; Thiaudiere, E.; Lecommandoux, S. Antibody-functionalized magnetic polymersomes: In vivo targeting and imaging of bone metastases using high resolution MRI. Adv. Heathc. Mater. 2013, 2, 1420-1424.

215. Huang, Z.H.; Teng, W.; Liu, L.S.; Wang, L.C.; Wang, Q.M.; Dong, Y.G. Efficient cytosolic delivery mediated by polymersomes facilely prepared from a degradable, amphiphilic, and amphoteric copolymer. Nanotechnology 2013, 24, doi:10.1088/0957-4484/24/26/265104.

216. Oliveira, H.; Perez-Andres, E.; Thevenot, J.; Sandre, O.; Berra, E.; Lecommandoux, S. Magnetic field triggered drug release from polymersomes for cancer therapeutics. J. Control. Release 2013, 169, 165-170. 
217. Debets, M.F.; Leenders, W.P.J.; Verrijp, K.; Zonjee, M.; Meeuwissen, S.A.; Otte-Holler, I.; van Hest, J.C.M. Nanobody-functionalized polymersomes for tumor-vessel targeting. Macromol. Biosci. 2013, 13, 938-945.

218. Spulber, M.; Najer, A.; Winkelbach, K.; Glaied, O.; Waser, M.; Pieles, U.; Meier, W.; Bruns, N. Photoreaction of a hydroxyalkyphenone with the membrane of polymersomes: A versatile method to generate semipermeable nanoreactors. J. Am. Chem. Soc. 2013, 135, 9204-9212.

219. Petersen, M.A.; Hillmyer, M.A.; Kokkoli, E. Bioresorbable polymersomes for targeted delivery of cisplatin. Bioconjugate Chem. 2013, 24, 533-543.

220. Qiao, Z.Y.; Ji, R.; Huang, X.N.; Du, F.S.; Zhang, R.; Liang, D.H.; Li, Z.C. Polymersomes from dual responsive block copolymers: Drug encapsulation by heating and acid-triggered release. Biomacromolecules 2013, 14, 1555-1563.

221. Stano, A.; Scott, E.A.; Dane, K.Y.; Swartz, M.A.; Hubbell, J.A. Tunable T cell immunity towards a protein antigen using polymersomes vs. solid-core nanoparticles. Biomaterials 2013, 34, 4339-4346.

222. Cui, H.G.; Chen, Z.Y.; Zhong, S.; Wooley, K.L.; Pochan, D.J. Block copolymer assembly via kinetic controlled. Science 2007, 317, 647-650.

223. Zhang, S.Y.; Zhao, Y. Rapid release of entrapped contents from multi-functionalizable, surface cross-linked micelles upon different stimulation. J. Am. Chem. Soc. 2010, 132, 10642-10644.

224. Tong, R.; Cheng, J.J. Anticancer polymeric nanomedicines. Polym. Rev. 2007, 47, 345-381.

225. Danhier, F.; Lecouturier, N.; Vroman, B.; Jerome, C.; Marchand-Brynaert, J.; Feron, O.; Preat, V. Paclitaxel-loaded PEGylated PLGA-based nanoparticles: In vitro and in vivo evaluation. J. Control. Release 2009, 133, 11-17.

(C) 2014 by the authors; licensee MDPI, Basel, Switzerland. This article is an open access article distributed under the terms and conditions of the Creative Commons Attribution license (http://creativecommons.org/licenses/by/3.0/). 